\title{
EL TRATAMIENTO RELIGIOSO EN LA CONSTITUCIÓN DE CÁDIZ
}

CAYETANO NÚÑEZ RIVERO 
SUMARIO

1. INTRODUCCIÓN. 2. LA IMPORTANCIA DE LA RELIGIÓN EN EL PROCESO CONSTITUYENTE. 3. EL TRATAMIENTO RELIGIOSO EN EL TEXTO CONSTITUCIONAL. 4. LA LEGISLACIÓN PRODUCIDA REFERENTE A ASUNTOS RELACIONADOS CON LA IGLESIA. 


\title{
EL TRATAMIENTO RELIGIOSO EN LA CONSTITUCIÓN DE CÁDIZ
}

POR

\author{
CAYETANO NÚÑEZ RIVERO \\ Profesor titular de Derecho Constitucional \\ UNED
}

\section{INTRODUCCIÓN}

El texto gaditano es considerado como la primera Constitución española, en cuanto se le considera consecuencia directa del poder constituyente de la nación española, manifestado a través de las Cortes reunidas al efecto.

Se trata por tanto, de uno de los primeros textos constitucionales representativos del Estado de Derecho, que proclama por tanto los principios básicos del primer Estado Liberal, teniendo solamente como antecedentes a la Constitución norteamericana de 1787 y al texto francés de 1791. Sin embargo, aunque difiere de estos textos citados en algunos aspectos, como es la forma de Gobierno y la organización territorial del Estado, en el caso norteamericano, o en la proclamación de los derechos y libertades en un cuerpo único como en el caso francés, la Constitución española de 1812, responde a los mismos principios y características de los textos anteriormente citados, que son los correspondiente al Estado Liberal en su primera formulación, incluso en lo concerniente a los derechos y libertades, aunque en el texto español no exista una específica declaración de los mismos, ni se agrupen en un título concreto, sin embargo, ello no quiere decir que no se recojan los derechos fundamentales y los principios inheren- 
tes a ellos a lo largo del mismo, ${ }^{1}$ de tal forma, que aunque a diferencia de otros textos constitucionales de la época, inspirados en el constitucionalismo galo, los derechos y libertades no se expongan de forma ordenada y sucesiva, la Constitución española de 1812, contiene como una de sus más importantes características una detallada exposición de derechos y libertades de carácter individual. $^{2}$

Sin embargo, la diferencia mayor que se observa en relación a los dos textos citados anteriormente, se produce en el campo de las libertades del ciudadano, en cuanto proclama la confesionalidad del Estado, impidiendo con carácter excluyente la práctica de cualquier otra. ${ }^{3}$

\section{LA IMPORTANCIA DE LA RELIGIÓN EN EL PROCESO CONSTITUYENTE}

La importancia de la religión católica se pone de manifiesto, ya en su origen, en el ceremonial aprobado por el Consejo de Regencia para la instalación de las Cortes, ${ }^{4}$ que reproducimos en su integridad por cuanto es muy representativo del sentimiento católico, que en la concepción de sus convocantes imperaba en los representantes de la Nación española, de tal forma, que la reunión de Cortes se nos presenta, no como un poder que se constituye para proclamar la soberanía de la Nación, sino como un poder constituido por la Religión.

«El Rey, nuestro Señor Don Fernando VII, y en su nombre el Supremo Consejo de Regencia de España e Indias, en el día en que debe verificarse la apertura e instalación de las Cortes generales del Reino, considerando que esta extraordinaria y tan deseada congregación, la más solemne y general de toda la Nación española, y de que no bay ejemplo en los siglos anteriores, es por el número, universalidad y modo de elección de sus representantes un Congreso, en que unidos por el amor y común interés, y más aún por la cristiana caridad los españoles de los dos mundos, tratan:

${ }^{1}$ El artículo 4, proclama que «La Nación está obligada a conservar y proteger por leyes sabias y justas la libertad civil, la propiedad y los demás derechos legítimos de todos los individuos que la componen».

2 Véase Cayetano Núñez Rivero; Rosa Ma Martínez Segarra; (1997). Historia Constitucional de España. Ed. Universitas, pág. 72 y ss.

3 Artículo 12.C.E 1812.

${ }^{4}$ Acordado y publicado en hoja suelta por el Consejo de Regencia en 23 de septiembre de 1810. 
- En primer lugar de defender, conservar y ampliar en ellos la verdadera Religión Católica Apostólica Romana, los derechos del legítimo Monarca, que Dios ba concedido a las Españas;

Los de esta Nación grande, empeñada gloriosamente en sostener su independencia y no ceder a la fuerza, artificios y tramas de la perfidia y de un poder que quiere bacerla esclava, dominándola y dándola Reyes que sean sus vasallos, ballando justo y legítimo cuanto la ambición puede sugerirle; $y$,

- Que sobre éste, su primero y principal objeto, extiende sus miras a cuanto puede contribuir a la mayor felicidad espiritual de 30 millones de babitantes en sus dominios de Europa, África, Asia y América.

En tales circunstancias tan piadosas, justas, nobles y magnánimas empresas para gloria de Dios y su santo servicio, resuelve por el presente decreto que a la instalación de las Cortes preceda la concurrencia a la iglesia parroquial de la isla de León, saliendo formados desde la sala de la Regencia con el Consejo Supremo los Diputados todos que se celebre Misa de pontifical votiva del Espíritu Santo, con su asistencia, con el Cardenal Arzobispo de Toledo, implorando así la divina protección, luces y sabiduría de lo alto: que cantándose antes o después de la Misa el bimno Veni Sancte Spiritus, inmediatamente se siga, previa una ligera insinuación, la profesión de la fe y el juramento que deben prestar los Diputados, y se cante el Te Deum por último. Después pasarán el Consejo de Regencia y los Diputados a Cortes en la misma forma que vinieron de la iglesia a la sala dispuesta para la celebración de las Cortes, en la que se verificará su instalación, retirándose luego el Consejo.

Tendréislo entendido para su cumplimiento.

PEDRO, Obispo de Orense, Presidente.- FRANCISCO DE SAAVEDRA.- XAVIER DE CASTAÑOS. - ANTONIO DE ESCAÑO.- MIGUEL DE LARDIZÁBAL Y URIBE.

Real isla de León, 23 de septiembre de 1810.

Un día más tarde, el 24 de septiembre se celebrará el Acto de Instalación de las Cortes Generales y Extraordinarias, cuya Acta firmada por el Nicolás María de Sierra, Secretario de estado y del Despacho de Gracia y Justicia, dice lo siguiente respecto a dicho evento:

«(..) babiendo becho que precediera una solemnísima rogativa pública por tres días, para implorar del Padre de las luces las que exigen para el acierto los sublimes objetos de un Congreso, (...)subsiguiéndose a esto el implorar de nuevo la inspiración divina por medio de la Misa del Espíritu Santo, que acordó el Consejo de Regencia, y debía celebrar de pontifical el Cardenal de Escala, Arzobispo de Toledo,... se dispuso que congregados todos los señores Diputados de las Provincias libres y suplentes de las ocupadas, en el Real Palacio de la Regencia, saliesen formados con el Consejo Supremo, y se dirigiesen a la iglesia parroquial en esta Isla, donde habia de celebrarse la Misa votiva del Espíritu Santo, cantarse antes o después el bimno Veni Sancte Spiritus, y enseguida, precediendo una ligera in- 
sinuación exhortatoria, se biciese por los señores Diputados y suplentes la profesión de la fe y el juramento que debian prestar. ... y dirigiéndose a la iglesia parroquial, se celebró por aquel Prelado la Misa, en la cual, después del Evangelio y de una breve y sencilla exhortación que hizo el Serenísimo señor Presidente don Pedro Quevedo, Obispo de Orense, se pronunció por mí por dos veces en alta voz la siguiente fórmula del juramento:

"¿Juráis la santa Religión Católica, Apostólica, Romana, sin admitir otra alguna en estos Reinos? ¿Juráis conservar en su integridad la Nación española, y no omitir medio para libertarla de sus injustos opresores? ¿Juráis conservar a nuestro muy amado Soberano el Señor Don Fernando VII todos sus dominios, y en su defecto a sus legítimos sucesores, $y$ hacer cuantos esfuerzos sean posibles para sacarlo del cautiverio y colocarlo en el Trono? ¿Juráis desempeñar fiel y legalmente el encargo que la Nación ha puesto a vuestro cuidado, guardando las leyes de España, sin perjuicio de alterar, moderar y variar aquellas que exigiese el bien de la Nación?».

Y habiendo respondido todos los señores Diputados: «Sí, juramos», pasaron de dos en dos a tocar el libro de los Santos Evangelios, y el señor Presidente, concluido este acto, dijo: «Si así lo biciereis, Dios os lo premie; y si no, os lo demande».

Se siguió inmediatamente el himno Veni Sancte Spiritus y el Te Deum entonado con gravedad y solemnidad, y finalizada esta función, desde la iglesia bajo la misma formación caminaron a la sala de Cortes, y, habiendo ocupado sus lugares los Sres. Diputa$\operatorname{dos}(\ldots)$.

Posteriormente, una vez constituidas las Cortes, y proclamado por las mismas el principio de soberanía nacional, la división de poderes, así como la inviolabilidad de los diputados, se procedió a fijar los términos del juramento que el Consejo de Regencia debía prestar ante las Cortes, que al igual que el anteriormente indicado contenía la expresión, «Juráis... ¿conservar la religión Católica Apostólica Romana,(...) mientras ponían la mano en los Santos Evangelios, ${ }^{5}$ lo que hicieron cuatro de los consejeros, ya que el Obispo de Orense no acudió con el pretexto de lo intempestivo de la hora y su delicada salud ${ }^{6}$. Así mismo, en el tercer decreto de las Cortes $^{7}$, se ordena que en todo el Reino, junto a la difusión de los dos primeros decretos, se proceda a cantar un solemne Te Deum en acción de gracias, así como rogativas públicas por tres días, implorando el auxilio divino para el acierto». ${ }^{8}$

5 La fórmula completa del juramente está publicada en el Decreto I de 24 de septiembre de 1810

${ }^{6}$ Acta de la sesión del 24 de septiembre de 1810.

7 Decreto III de 25 de septiembre de 1810.

${ }^{8}$ La profusión de actos religiosos en la conmemoración de efemérides nacionales, se mantuvo durante todo el proceso constituyente, valgan como ejemplos el Decreto LXII de 2 de mayo de 1811 , por el que ordena que el aniversario del 2 de mayo, las iglesias mayores de los pueblos ce- 
Con lo expuesto hasta el momento, queda clara la importancia que los principios religiosos tenían en la configuración estatal española, así como el sentimiento católico mayoritario de los constituyentes españoles, entre los que había un elevado número de religiosos ${ }^{9} .{ }^{10}$

Sobre la catolicidad de los constituyentes y el ejercicio de la misma, existen numerosas pruebas, tanto en los debates de las Cortes Constituyentes, como en los Decretos publicados, valga al respecto, el Decreto $\mathrm{XV}^{11}$, dirigido al clero, en el que las Cortes, ante el intento de José I de atraerse al clero español, especialmente al bajo clero regular, tras el avance de las tropas bonapartistas en Andalucía ${ }^{12}$, procede a denunciar los intentos bonapartistas de control de la Iglesia española, e

lebren actos solemnes, así como el Decreto LXIX de 22 de mayo de 1811, que ordena que Catedrales, Colegiatas, Parroquias y demás centros religiosos celebren solemnes funciones religiosas el día de San Fernando en memoria de los perecidos en la guerra El Decreto XCIV de 22 de septiembre de 1811, que ordena la celebración de un Te Deum en celebración del aniversario de la instalación de las Cortes.

9 Véase al respecto, Núñez Rivero, Cayetano (2011) «La cuestión religiosa en las Cortes de Cádiz» Ed. Cortes Valencianas, El grupo de eclesiásticos era sensiblemente mayor al de cualquier otro colectivo profesional, siendo más de un tercio que el de abogados, o el de funcionarios, grupos que le seguían en número de miembros, representando algo menos de la tercera parte de los diputados constituyentes, conformado por seis obispos, cuarenta y seis canónigos, y otros cuarenta y dos presbíteros, en general altamente cualificados: adviértase que entre ellos se contaban catedráticos, capellanes, un bibliotecario y un secretario episcopal — dieciocho eran párrocos en iglesias generalmente urbanas y de cierta importancia- y de diez sólo conocemos su condición clerical; véase López Calvo, (2009) Cátedra. Revista Eumesa de Estudios; Vid. igualmente. Morán, M. (1990); «Los diputados eclesiásticos en las Cortes de Cádiz: revisión crítica»; en «Hispania Sacra» 42.; Higueruela del Pino, Leandro «La Iglesia y las Cortes de Cádiz».

${ }_{10}$ No obstante, debe destacarse el elevado número de religiosos en España, (censo de 1797: 2.051 conventos con 53.178 religiosos profesos y 16.481 párrocos y 41.009 beneficiados de todas clases; Fuente Palacio Atard, Vicente (1981); «La España del siglo XIX»; Ed. Espasa, pág. 78. Otras fuentes más recientes sitúan el número de religiosos en cerca de 150.000; Suárez Bilbao, Fernando; «Las Cortes de Cádiz y la Iglesia»; «En Cortes y Constitución de Cádiz»; Espasa 2011. Tomo II. pág. 61.

11 Decreto de 1 de diciembre de 1810.

12 Decretos de José I, de 8 de noviembre de 1809, 13 de junio, 20 de agosto, 21 de septiembre y 31 de octubre de 1810 por el que se fija una pensión para las monjas, así como para las que deseen abandonar la clausura. Respecto los ex Regulares, véase Decreto de 11 de octubre de 1809, por el que se fija pensión a los que han sido Generales o Vicarios Generales de dichas Órdenes. Decretos de 17 de septiembre de 1809 y Decreto de 6 de junio de 1810, por el que se asegura el pago de los ex Regulares. Pueden destacarse igualmente, entre otros, el Decreto de 1 de mayo de 1810 por el que manda se provean en Sacerdotes y ex Regulares los oficios de Sacristán en Andalucía; en dicho decreto es de resaltar la crítica que hace a la jerarquía eclesiástica, por haber concedido dichos oficios a personas sin capacitación. Decreto de 11 de abril de 1810, «En el que se establece y fixa la dotación de de los veinticinco Curatos de Sevilla». 
identifica la defensa de la patria con la religión y con la labor que las Cortes están llevando a cabo en ese momento, «(...) hagan presente que es indispensable sacrificarlo todo, y guerrear hasta morir, porque peligran la Religión y la Patria; que es la voluntad de Dios, autor y protector de las sociedades, y un precepto natural que repiten é inculcan nuestros códigos», utilizando al respecto un lenguaje religioso, «que el amor de la $\mathrm{Pa}$ tria, de su libertad é independencia, (...) es la acción más gloriosa que recomiendan las sagradas letras; enseñen penetrados del espíritu de los Macabeos, que se debe promover la santa causa que se ha emprendido(...)», finalizando dicho Decreto con una exhortación al clero para «(...) atraer las bendiciones del cielo, mediante rogativas públicas y privadas».

Sin embargo, en las Cortes constituyentes, pronto se van a producir debates que tendrán un trasfondo religioso y que posibilitarán que se decanten dos posturas, una que podemos definir como claramente liberal y reformista, que hunde sus raíces en la Ilustración y en las experiencias constitucionales francesa e inglesa, y otra de carácter conservadora que se justifica en la tradición española y en el soporte ideológico que representa la Iglesia Católica.

Para el sector liberal, su primera conquista había sido la proclamación de la soberanía nacional y la división de poderes, lo que aconteció en la primera sesión de Cortes, sin que en este intento, salvo la excepción del Obispo de Orense, D. Pedro de Quevedo y Quintano, que negó juramento al principio de soberanía nacional, hubiera oposición por parte de los representantes del denominado sector conservador o «servil».

Sin embargo, en la concepción de los liberales, las Cortes y el proceso constituyente significaban, no sólo la organización del poder político de España como contrapartida al cambio de dinastía y la «invasión» francesa, sino también, la posibilidad de acabar con el Antiguo Régimen, para lo cual, era preciso proclamar una serie de derechos y libertades, entre las que figuraba en destacado lugar la libertad de expresión e imprenta que era considerada por los liberales como uno de los principios nucleares del nuevo sistema político que se pretendía implantar ${ }^{13} \cdot{ }^{14}$ Sin embargo, esta conquista de carácter irrenunciable para los liberales, ${ }^{15}$ sería considerada por los diputados más conservadores como algo incon-

13 Fernández Segado, Francisco, (2004) «La libertad de imprenta en las cortes de Cádiz» Revista de estudios políticos, nº 124, pág. 29.

${ }_{14}$ Como indica La Parra López, Emilio (2004); «La libertad de prensa en las Cortes de Cádiz»; Nau LLibres. Valencia pág. 37; Los liberales basaron la defensa del decreto de libertad de imprenta en cuatro grandes argumentos: es un derecho del ciudadano, constituye un vehiculo esencial para la ilustración del pueblo, es una garantía para atajar el mal gobierno así como a los gobernantes que se aparten del interés general y, por último, resulta necesaria en las circunstancias del momento.

15 No debe olvidarse, que uno de los primeros actos de los constituyentes franceses fue la proclamación de la misma, haciéndolo en la Declaración de los Derechos del Hombre del Hombre y 
ciliable con los cánones y la disciplina de la Iglesia, ${ }^{16}$ y "aún con el mismo dogma católico, en que reside la inmutable verdad», como indicara el diputado eclesiástico Sr. Morros ${ }^{17}$; no obstante la oposición conservadora y la obstrucción a su desarrollo, con aspectos como que el proyecto debía ser informado por el Tribunal del Santo Oficio y las autoridades eclesiásticas, así como que debía esperarse a que las Cortes estuvieran formadas por la totalidad de los diputados, (diputado Tenreyro $)^{18}$ no impidieron que el tema de la libertad de expresión e imprenta fuera abordado por los constituyentes gaditanos, desde casi el mismo inicio de los trabajos parlamentarios, así, fue planteado en Cortes el 24 de septiembre de 1810 , en pleno comienzo del proceso constituyente, presentándose el Proyecto el 8 de octubre y siendo aprobado tras arduo debate el 5 de noviembre, ${ }^{19}$ proclamándose en la temprana fecha del 10 de noviembre de 1810, mediante el decreto $\mathrm{n}^{\circ} 9$.

En el mismo, en su exposición de motivos se resume la ideología liberal respecto a la libertad de pensamiento e impresión, «Atendiendo las Cortes generales y extraordinarias a que la facultad individual de los ciudadanos de publicar sus pensamientos e ideas políticas es no sólo un freno de la arbitrariedad de los que gobiernan, sino también un medio de ilustrar a la Nación en general, y el único camino para llevar al conocimiento de la verdadera opinión pública, (...).» ${ }^{20}$.

Sin embargo, la rapidez del proceso no quiere decir que el mismo estuviera exento de dificultades, debiendo destacarse que fue la primera vez en las Cortes, que un tema de trasfondo religioso iba a ser objeto de debate en la Cámara que solo fue superado una vez que el bando liberal aclarara que la libertad solicitada no se refería a materias eclesiástica, sino al ámbito político ${ }^{21}$. No obstante, debe indicarse, que en el momento que se produce el debate, había dos aspectos que coadyuvarían a su buen fin. A tal efecto, debe recordarse, que con anterioridad el

del Ciudadano, en su artículo 11»La libre comunicación de pensamientos y de opiniones es uno de los derechos más preciados del hombre; todo ciudadano puede, por tanto, hablar, escribir e imprimir libremente, con la reserva de responder del abuso de esta libertad en los casos determinados por la ley»

16 Diario sesiones del 14 de octubre de 1810. También puede verse un amplio resumen de estos debates, analizados desde un punto de vista muy conservador en Menéndez Pelayo «Historia de los heterodoxos españoles». vol. II. Págs. 800 a 816. Biblioteca de autores cristianos. Madrid. 1956.

17 Francisco Morros y Cibila, párroco y diputado por Cataluña.

18 Joaquín Tenreyro y Montenegro; conde de Vigo y diputado por Galicia.

19 Fue aprobado por 68 votos a favor y 32 en contra.

20 Exposición de motivos del Decreto de Libertad política de la imprenta de 10 de noviembre de 1810

${ }^{21}$ No deja de ser interesante esta afirmación sostenida por el diputado americano Mejía, en un país, en el que hasta ese momento al menos, se tendían a confundir los ámbitos público y religioso. 
Estatuto de Bayona, ya la había proclamado ${ }^{22}$; así mismo, en la práctica, durante este periodo y como consecuencia del vacío de poder existente se publicaban numerosos folletos, de diferentes tendencias, de muy difícil control por parte de las autoridades, que suministraban información sobre los asuntos de la guerra, pero también sobre los debates en Cortes ${ }^{23}$ siendo algunos de matiz claramente anticlerical $^{24}$

Sin embargo, ya en el citado Decreto se van a fijar los límites de la libertad de expresión y del rol que jugará la Iglesia católica en el régimen político naciente, en lo que se refiere al control de la libertad de pensamiento. Así, aunque se proclame la libertad de publicación y se elimine la censura previa ${ }^{25}$, mediante el artículo 6 del citado Decreto, se manifiesta que serán objeto de censura previa «Todos los escritos sobre materias de religión», asignándola «a los Ordinarios eclesiásticos, ${ }^{26}$ según lo establecido en el Concilio de Trento», lo que vaciaba en cierto sentido al principio proclamado en el artículo 2 del citado Decreto, que manifestaba que «Por tanto quedan abolidos todos los actuales juzgados de Imprenta y la censura de las obras políticas precedente a su impresión», de lo que se derivaba, que en lo sucesivo, serían responsables los autores e impresores, una vez que hubieran cometido abuso de dicha libertad de expresión y no antes, ${ }^{27}$ determinándose, que «Los libelos infamatorios, los escritos calumniosos. Los subversivos de las leyes fundamentales de la Monarquía, los licenciosos y contrarios a la decencia pública y buenas costumbres serán castigados con la pena de la ley, y las que aqui se señalarán; ${ }^{28}$ de esta forma,

22 En dicha Carta, se trata de la libertad de imprenta en los artículos, 39, 40, 45, 46,47 y 48, proclamándose la misma en el artículo 145, aunque su ejecución se posterga a la existencia de una ley específica, que no se publicaría hasta pasados dos años de la vigencia plena del Estatuto.

${ }_{23}$ Cabe destacar entre otros, el Diario Mercantil, el Diario de la Tarde, el Duende de los cafés, La Abeja española, el Conciso,el Tribuno español, El Obsevador, la Gaceta del comercio etc.

${ }^{24}$ Sobre los escritos anticlericales, destaca sobremanera, por su nivel intelectual y difusión el libro «El diccionario crítico burlesco del que se titula Diccionario razonado manual para inteligencia de ciertos escritores que por equivocación han nacido en España» (1811), Imprenta del Estado Mayor general, Cádiz, publicado primero de forma anónima, pero cuya autoría corresponde a D. Bartolomé José Gallardo, bibliotecario de las Cortes; descubierta su autoría fue confinado en el Castillo de Santa Catalina»

25 Arts. 1 y 2.

${ }^{26}$ No obstante, aunque los libros de religión no pudieran imprimirse sin licencia del Ordinario, éste no podía negarla sin previa censura y audiencia del interesado (art19), y en el caso de que el Ordinario insistiese en negar su licencia, el interesado podía acudir con copia de la censura a la Junta Suprema, la cual debía examinar la obra, y si la hallase digna de aprobación, pasaba su dictamen al Ordinario, para que «más ilustrado sobre la materia, conceda la licencia, si le pareciere, a fin de excusar recursos ulteriores» (art. 20).

27 Artículo 3.

28 Artículo 4. 
se encargaba, al igual que en los restantes delitos a los Jueces y Tribunales que entendieran «en las averiguación, calificación y castigo de los delitos que se cometan por el abuso de la libertad de la Imprenta, arreglándose a lo dispuesto por las leyes y en este reglamento». ${ }^{29}$

De esta forma, en virtud de la patente contradicción existente en el citado Decreto, se procedía a mantener la censura previa de expresión sobre la religión, de manera, que los escritos sobre esta materia precisaban de la previa licencia de los «Ordinarios», pudiendo sufrir pena pecuniaria, sin perjuicio de la que, en razón del exceso en que incurriera el autor o editor, tuviera establecida en las leyes, lo que venía a significar una doble pena. ${ }^{30}$

Por otra parte, con el fin de asegurar la libertad de imprenta y contener al mismo tiempo su abuso, las Cortes procedían a nombrar una Junta Suprema de Censura compuesta de nueve miembros, y a propuesta de ésta, otras semejantes en cada capital de provincia, compuesta en este caso por cinco miembros, ${ }^{31} \sin$ embargo, la importancia concedida a la Iglesia se pone de manifiesto en el hecho de que la Junta Suprema de Censura debía contar con tres eclesiásticos, así como con dos las provinciales. ${ }^{32}$

La libertad de expresión quedaría definitivamente promulgada mediante el artículo 371 del texto constitucional «Todos los españoles tienen libertad de escribir, imprimir y publicar sus ideas politicas sin necesidad de licencia, revisión o aprobación alguna anterior a la publicación, bajo las restricciones y responsabilidad que establezcan las leyes». ${ }^{33}$

De esta forma, la libertad de imprenta en España nacía bajo la limitación de las ideas religiosas, no sólo por no poder expresarse sobre este tema sin la pre-

29 Artículo 5.

30 Artículo 12.

31 Artículo 13.

32 Artículo 14.

33 Mediante el Decreto CCLXIII, de 10 de junio de 1813 «Adiciones á la ley de libertad de Imprenta», se hacían dos importantes adiciones que afectaban al clero; en la primera se proclamaba que «Las obras que los prelados eclesiásticos, así seculares como regulares, publicaren baxo el concepto de escritores particulares, seguirán los trámites que las de los demás ciudadanos» Art. XXXI; la segunda es de especial relevancia, pues se refería al establecimiento de un cierto control de legalidad sobre publicaciones oficiales de la Iglesia: pastorales, instrucciones ó edictos, "que los M.RR.Arzobispos, RR. Obispos y demás prelados y jueces eclesiásticos impriman y dirijan á sus diocesanos en el exercicio de su sagrado ministerio»; en este caso, si el contenido de dichos escritos contenían «cosas contrarias á la Constitución ó á las leyes, el Rey, y en su caso la Regencia», se pasaba el mismo al Consejo de Estado, suspendiendo su curso y recogiendo los existentes. "Si además hallare méritos para formación de causa que induzca desafuero contra el autor ó autores, pasará á este fin el impreso al Tribunal Supremo de Justicia, siempre que éste sea de Arzobispo ú Obispo, y á la Audiencia territorial si fuere de alguno de los demás prelados y jueces eclesiásticos». Art. XXXII. 
ceptiva autorización eclesiástica, y ello, en un país, donde la confusión entre lo público y lo religioso era notoria, y donde la legitimación del poder durante el Antiguo Régimen, como se indicó anteriormente se había llevado a cabo fundamentalmente por la Iglesia, sino también por la desmesurada proporción de eclesiásticos en las Juntas Supremas y Provinciales de Censura. Posteriormente, la proclamación de confesionalidad del Estado y el carácter excluyente de cualquier otro culto, proclamado en el texto constitucional, pondrían de manifiesto el largo y difícil camino que todavía le quedaba al país para una auténtica libertad de prensa. ${ }^{34}$

\section{EL TRATAMIENTO RELIGIOSO EN EL TEXTO CONSTITUCIONAL}

La confesionalidad del texto se percibe claramente en diversas partes del mismo, así como en el Discurso Preliminar presentado a las Cortes por la Comisión, con motivo de la presentación del proyecto de Constitución, así, desde el Preámbulo, en el que se que se refiere a Fernando VII como Rey de las Españas «por la gracia de Dios,» ${ }^{35}$ dándole posteriormente el tratamiento de «Majestad Católica, ${ }^{36}$ y procediendo a la invocación «En el nombre de Dios todopoderoso, $\mathrm{Pa}$ dre, Hijo, y Espíritu Santo, autor y supremo legislador de la sociedad», manifestación alejada del constitucionalismo, contemporáneo indicado anteriormente, que sólo se reproducirá en el naciente constitucionalismo hispanoamericano posterior. No obstante, debe resaltarse, que a pesar de la marcada confesionalidad del citado preámbulo, éste no estuvo exento de discusión cuando la comisión constitucional lo presentó al pleno en la sesión del 25 de agosto de 1811, de tal forma, que dicha invocación religiosa, fue considerada insuficiente por el sector más conservador y normalmente eclesiástico de la Cámara, valga como ejemplo la intervención del diputado Guereña ${ }^{37}$. «Cuando un Congreso tan augusto como el que representa á la católica nación española ba jurado con solemnidad defender nuestra religión sacrosanta, y pone a los ojos de los españoles mismos la constitución política que perpetuará sus felicidades, entre los que son sin duda alguna de más dignidad y preferencia las que

34 Véase al respecto, Núñez Rivero, Cayetano; «La cuestión religiosa...» ob, ant, cit.

${ }^{35}$ Fórmula que se utilizará igualmente en la promulgación de las leyes, «(El Rey), por la gracia de Dios...»Artículo 155.C:E 1812., así como en el juramento del Rey. Artículo 173.C:E: .1812,: así como en el supuesto de Regencia, Artículo 196.

36 Artículo 169. C.E. 1812.

37 Juan José Ignacio Guereña y Garayo, propietario de la canonjía doctoral de la catedral de Puebla, Diputado por Durango (Nueva Vizcaya), 1810. 
pertenecen al espíritu, me parece escasa, ó demasiado concisa la expresión que sólo habla de Dios trino y uno, como autor y legislador supremo de la sociedad, pudiendo en pocas lineas extenderse una protestación de los principales misterios, Induce a pensarlo así, el ilustre ejemplo que advertimos en nuestra legislación, examinada desde sus más remotas épocas. Notamos, pues en los Fuero Juzgo y Real, el sabio Código de las Partidas, en las Recopilaciones Nueva y Novísima de Castilla, y en la que se formó para las Indias, el esmero con que se preconiza nuestra fe, y el elogio con que se recomiendan todas sus máxima. Igual conducta han observado los cuerpos legislativos eclesiásticos, como es de ver en el común de los cánones y en los Concilios generales, nacionales y provinciales. Y por último, según la idea que inspira el simbolo der San Anastasio, adoptado por la Iglesia, la fe del cristiano es confesar los principales dogmas de ella. Así que para desempeñar acerca de este importantísimo objeto nuestro deber, y la confianza de una Nación, que tiene por la primera de sus glorias la de ser y presentarse católica, apostólica, romana, convendría incluir en una fórmula, aunque breve los artículos más necesarios». Argumentación que fue igualmente defendida y sostenida por otros miembros de la Cámara, como el diputado Riesco ${ }^{38}$, «aún puede indicarse más la religión que profesa la Nación, según está prevenido por las leyes, porque si en los testamentos, que son leyes particulares de la familia, se pone la protestación de la fe, mucho más se debe poner en ésta, que es una ley constitucional, por lo cuál pudiera añadirse alguna expresión con la cual diese VM al mundo entero un testimonio de que renueva los sentimientos del gran Recaredo, Sisenando, Suitila y otros. Los Concilios de Toledo IV, VI y XVI, Y cuantas prestaciones de fe ba becho la Nación, todas están conformes con esto». Otras intervenciones como la del diputado, Sr Creus ${ }^{39}$, querían introducir en el texto constitucional el dogma de la Santísima Trinidad, así como Simón López ${ }^{40}$ y Villagómez ${ }^{41}$ que pretendían que el texto contuviera una referencia a la encarnación del hijo de Dios y de la «Purísima Virgen María, «conforme se hace en los Concilios se proviene en la ley de Partida» Algunos diputados: Sr. Lera ${ }^{42}$ y D. Aguiriano Gómez ${ }^{43}$, ponen de manifiesto la confusión entre las funciones de un texto constitucional y el concepto de catecismo cristiano, función didáctica que en su opinión debía tener el texto constitucional,

38 Francisco María Riesco, diputado por Extremadura; fue consejero de Castilla e Inquisidor del Tribunal de Llerena, siendo Decano de la Inquisición en Extremadura y vocal de la Junta Superior.

39 Jaime Creus y Martí, diputado por Cataluña, eclesiástico, que durante el periodo absolutista de Fernando VII llegaría a ser Obispo de Menorca y Arzobispo de Tarragona.

${ }^{40}$ López García, Simón. Obispo de Orihuela y Arzobispo de Valencia. Representaba a Murcia.

41 Miguel Jerónimo Alfonso Villagómez y Lorenzana. Diputado por León.

${ }^{42}$ Juan de Lera y Cano, Obispo de Barbastro y Segovia, representante de La Mancha.

43 Francisco Mateo, Aguiriano Gómez. Obispo de Calahorra y la Calzada. Representante por Burgos.

(C) UNED. Revista de Derecho Político

N. ${ }^{\circ}$ 82, septiembre-diciembre 2011, págs. 351-390 
«Aquí se trata de una Constitución elemental para España(...) pero el primer punto que ha de tener presente ha de ser la religión católica y la creencia de esta religión; y como se ba de enseñar en las escuelas, será puesto en razón que la primera leche que ban de mamar los niños sea el conocimiento de que Dios es el autor de de todo. Que es el salvador, remunerador, justo, etc. Póngase creo firmemente esto, lo otro y lo de más allá. Póngase que Dios es el autor de todas las cosas, de todo lo visible e invisible, y que nos redimió; y también se hará como se debe poniendo: creo todo lo que dice la Santa Iglesia católica, apostólica, romana».

La defensa del proyecto de Constitución llevado a cabo por los diputados liberales participantes en el debate, tampoco puede considerarse ajeno al manejo de términos teológicos; valga como ejemplo la respuesta realizada por el diputado Sr.Espiga ${ }^{44}$ a la intervención del Obispo de Calahorra: «Cuando V. M encargó á la comisión el proyecto de de Constitución, creyó que no le encargaba un catecismo de la religión, y que este grande objeto de política no debía contener aquellos artículos que deben mamar los niños con la leche. La Constitución solo debe contener las leyes fundamentales, y lo que se dice en la Constitución, no solo expresa cuanto ban dicho los Concilios, sino cuanto ban dicho los Padres de la Iglesia. La Constitución dice: "La Nación española profesa la religión católica, apostólica romana, única verdadera, con exclusión de cualquier otra" ¿Qué cosa habrá que no esté contenida en este artículo? Se dice que se podía haber expresado el misterio de la Santísima Trinidad. Señor, cualquiera que haya leído los Padres y los intérpretes, deberá conocer que en estas palabras está la unidad de la esencia y la distinción de las personas, y no bay teólogo, por ignorante que sea, que no sepa esto. La magestad de una Constitución consiste en decir bajo pocas palabras cuanto se puede desear. También ha tenido presente la comisión que iba á poner su obra bajo la protección del autor de todas las cosas, y por eso ba dicho "en el nombre de Dios Todopoderoso, etc." No creía que fuese menester más que invocar el nombre de Dios Todopoderoso, como que es el autor del órden, de la justicia y de las leyes; el que formó al hombre con todas las cualidades necesarias para la sociedad, y que por esto se dice con la mayor exactitud autor y supremo legislador de la sociedad».

Sin embargo, este debate más propio de un Concilio, que puede parecer, al menos improcedente en unas Cortes constituyentes que trataban de proclamar el Estado de Derecho, en la opinión que sostenemos, por parte de los diputados eclesiásticos intervinientes respondía a un fin muy claro, que podemos caracterizar por los siguientes aspectos:

44 José Espiga Gadea. Diputado por Cataluña, Arcediano de Benasque (jurisdicción eclesiástica de Lérida); acusado de jansenita y regalista, fue el más destacado eclesiástico dentro del sector liberal de las Cortes, contaba con un gran conocimiento de la obra de Siêyes y del constitucionalismo francés. Entre otras intervenciones en el mismo sentido, podemos destacar la del diputado por Querétaro, Mariano Mendiola Velarde. 
a) Marcar los límites de la actuación del poder constituyente.

b) Dejar sentado el principio de la existencia de la denominada Constitución Histórica o Interna.

De esta forma, establecido el principio de que el país contaba con una Constitución desde tiempo inmemorial y de que ésta se asentaba en tres pilares básicos: Corona, Cortes e Iglesia Católica, la capacidad de actuación del poder constituyente queda muy mermada, ya que aunque en el texto se proclamara el principio de soberanía nacional, el ejercicio de este principio quedaba supeditado en cierta medida a por los principios conformadores de la Nación; es por ello la importancia de que en lugar tan destacado del texto como es el Preámbulo, sea éste considerado de carácter normativo o simplemente interpretativo del resto de la Constitución, se afirmara no sólo la confesionalidad del Estado, sino incluso los principios y dogmas de la Iglesia Católica.

Se ha considerado por la mayor parte de historiadores y constitucionalistas que el sector liberal de las Cortes obtuvo un importante triunfo al conseguir que en la sesión del 25 de agosto, primer día que se abrió el debate sobre el proyecto constitucional elaborado por la Comisión correspondiente, se aprobara el Preámbulo del texto ${ }^{45}$, valorándose la actitud conciliadora de sus miembros, que impidieron que el texto resultara un injerto de Constitución y de Catecismo canónico.

Sin embargo, deben valorarse dos aspectos que acaecieron ese día:

$1^{\mathrm{a}}$. Se aceptó el principio de existencia en el Reino de una Constitución histórica. Ello, no sólo por los argumentos utilizados por los liberales para rebatir los correspondientes al sector eclesiástico absolutista, sino por el propio texto del Discurso preliminar del proyecto constitucional expuesto por Arguelles ante el Pleno. ${ }^{46}$

45 Sólo se cambiaron dos términos que nada tenían que ver con el asunto religioso; su sustituyó la palabra notable por estable y bienestar por bien.

46 Nada ofrece la Comisión en su proyecto que no se halle consignado del modo más auténtico y solemne en los diferentes cuerpos de la legislación española, sino que se mira como nuevo el método con que ha distribuido las materias, ordenándolas y clasificándolas para que formasen un sistema de ley fundamental y constitutiva en el que estuviese contenido con enlace, armonía y concordancia quanto tienen dispuesto las leyes fundamentales de Aragón, de Navarra y de Castilla en todo lo concerniente á la libertad é independencia de la Nación, á los fueros y obligaciones de los ciudadanos, á la dignidad y autoridad del Rey y de los tribunales, al establecimiento y uso de la fuerza armada y método económico y administrativo de las provincias. Estos puntos capitales van ordenados sin el aparato científico que usan los autores clásicos en las obras de política ó tratados de Derecho público que la Comisión creyó debía evitar por no ser necesario cuando no fuese impropio en el breve, claro y sencillo testo de la ley constitutiva de una monarquía. Pero al mismo tiempo no ba podido menos de adoptar el método que le pareció más análogo al estado presente de la Nación, en que el adelantamiento de la ciencia del Gobierno ha introducido en Europa un sistema desconocido en los tiempos en que se publicaron los diferen- 
$2^{\circ}$. Se aceptó el principio religioso como conformador de la Nación española ${ }^{47}$ e inspirador de la actuación de la misma, tanto en lo que se refería al pasado, como en el nuevo sistema que se implantaba. ${ }^{48}$

El artículo 12 del texto, correspondiente Capítulo II del título II, proclama sin ambigüedad alguna la confesionalidad del Estado y el carácter intolerante al respecto y excluyente de la religión católica respecto a cualquier otro credo religioso, «La Religión de la Nación española es y será perpetuamente la Católica, Apostólica, Romana, única verdadera. La Nación la protege por leyes sabias y justas y probíbe el ejercicio de cualquiera otra...» ${ }^{49}$.

En el Proyecto previo la formulación del artículo, aunque respondía a los mismos principios que el texto definitivo, no incluía la afirmación de «es y será permanentemente católica», limitándose a proclamar que era la profesada por la $\mathrm{Na}$ ción española, quedando igual en el resto. La explicación del cambio en el texto, se manifiestan en el Discurso Preliminar de la Comisión, en virtud de la importancia del objeto tratado, «La declaración solemne y auténtica de que la religión cató-

tes cuerpos de nuestra legislación, sistema del que ya no es posible prescindir absolutamente, así como no lo bicieron nuestros antiguos legisladores, que aplicaron á sus reynos de otras partes lo que juzgaron útil y provechoso

47 Aunque hay varias referencias en el citado discurso preliminar, valga como ejemplo lo manifestado referente a la proclamación del Príncipe de Asturias «Igualmente ha parecido oportuno que el Príncipe de Asturias, luego que llegue á los catorce años, jure ante las Cortes defender la religión católica, apostólica, romana, guardar la Constitución y obedecer al Rey, ya porque en esta edad puede contraer matrimonio y ser considerado como en estado libre, ya porque el respeto, obediencia y fidelidad á la religión, á la ley y al Rey empiezan á ser desde este tiempo los vínculos que le unen más estrechamente á la Nación, que algún día habrá de gobernar.

${ }^{48}$ Valga como ejemplo la intervención del diputado por Chile Joaquín Fernández Leiva, adscrito al sector liberal, que en el debate, en defensa de los términos planteados por la Comisión constitucional, y con el fin de contentar al sector integrista, haría una manifestación de la indisoluble unión de la religión y la Nación española, «La comisión ha creído que siendo la invocación de la Santísima Trinidad el principio de de nuestras instituciones, y la primera señal del cristiano, debió concebirse en los términos del proyecto. Pretender que se coloque enseguida la profesión de la fé es salir del órden y sacar este artículo de su lugar natural. La Nación española es la que vá a reiterar dicha profesión. Así, es preciso anticipar los elementos constitutivos de esta Nación. Cumplido este antecedente en el título I, y designado su territorio en el primer capítulo del título II, viene oportunamente el art 13, que dice así, "La Nación española profesa la religión católica, apostólica, romana, única verdadera, con exclusión de cualquiera otra". Estas dos líneas contienen las adiciones de los señores preopinantes, siendo indudable que la fé ortodoxa fundada en la palabra divina y en la unidad de los fieles bajo la suprema potestad pastoral del sucesor de San Pedro, tiene por objeto cuanto la Iglesia canoniza y reconoce por cierto. Es inútil hablar de Concilios generales o ecuménicos; sus decisiones son respetadas universalmente y tenidas por cánones infalibles de la religión católica en materias de fé y costumbres. Por tanto, el que profesa la religión, profesa, entre otras cosas la obediencia a los concilios».

${ }^{49}$ En el proyecto original la referencia a la confesionalidad del Estado se ubicaba en el artículo 13.Debe destacarse, que en la comisión encargada de redactar el citado artículo no hubo discrepancias al respecto. 
lica, apostólica, romana es y será siempre la religión de la Nación española, con exclusión de cualquiera otra, ha debido ocupar en la ley fundamental del Estado un lugar preeminente, cual responde a la grandeza y sublimidad del objeto».

No obstante, aunque el citado artículo fuera aprobado al día siguiente de su presentación a la Cámara, ello no obsta, para que se produjeran algunas intervenciones al respecto, que podemos considerar altamente representativas del parecer al respecto del bando conservador,entre las mismas, merece nuestro objeto de atención la protagonizada por el Sr. Inguanzo ${ }^{50}$ el día 2 de septiembre de 1811. En su alocución, que en virtud de su importancia reproducimos íntegra a continuación, expone tres puntos básicos que significan el núcleo del pensamiento político al respecto, del sector católico conservador español y que impregnará no sólo el texto de Cádiz, sino la vida política española por más de un siglo:

a) Que la religión católica es la primera y más importante fuente del Derecho español.

b) Que la confesionalidad católica del Estado debe tener un carácter excluyente.

c) Que el elemento sustancial de la Nación y del concepto de nacionalidad española es la religión católica. Debiendo excluirse de la misma a aquellos que no la profesen.

«Decir que la Nación española profesa la religión católica, vida política española es decir un puro becho. Un hecho no es una ley, no induce obligación, y aqui se trata de leyes, $y$ leyes fundamentales. "Que la Nación española profesa la religión católica;" esta proposición no dice más que una anunciativa como esta: "los musulmanes profesan la religión de Maboma, los judíos la de Moisés". La religión debe entrar en la Constitución como una ley que obligue a todos los españoles á profesarla, de modo que ninguno pueda ser tenido por tal sin esta circunstancia. La religión es la primera de todas las leyes fundamentales, porque todas las demás estriban en ella; y sin ella, y sin los preceptos que por ella comunica su divino autor, no tienen fuerza ni obediencia las leyes humanas, y todo el edificio de la sociedad viene por tierra. Es también la más esencial, porque la Nación será tan Nación siendo monárquica como democrática, ú otro cualquier Gobierno; pero no será tan religiosa no siendo católica, y debe serlo igual en toda forma de gobierno. Así, me opongo á que el artículo corra como viene, y me parece que debe extenderse de modo que abrace los extremos indicados: esto es, que se proponga como ley primera y antigua fundamental del Estado, que debe subsistir perpetua-

50 Pedro Inguanzo y Rivero. Diputado por Asturias calificado por Menéndez Pelayo como el director del partido católico en las Cortes. A la vuelta del Absolutismo con Fernando VII, fue nombrado obispo de Zamora y posteriormente Arzobispo de Toledo. 
mente, sin que alguno que no la profesa pueda ser tenido por español, ni gozar los derechos de tal». ${ }^{51}$

El debate sobre la religión se llevó a cabo el 2 de septiembre de 1811, sin que se produjeran en el mismo, intervenciones contrarias a la confesionalidad excluyente del Estado ${ }^{52}$, a pesar de que previamente se hubieran aprobado los citados decretos que proclamaban la libertad de expresión e imprenta. Concluido el debate, la Comisión Constitucional presentó al día siguiente el texto reformado, que quedó aprobado el 3 de septiembre.

Cabe resaltar, que en el citado artículo constitucional se excede el ámbito jurídico propio del caso, para incidir en aspectos sociológicos, del presente y del futuro «La religión de la Nación española es y será perpetuamente la católica, apostólica romana...» así como en otros propios conceptuales de una religión concreta, de carácter dogmático: «única verdadera», a la que hay que unir el Preámbulo con la declaración de fe trinitaria.

La protección de la Iglesia por parte del Estado y el carácter excluyente de la misma se pone de nuevo de manifiesto en el juramento que el Rey debe hacer ante las Cortes en el momento de su advenimiento al trono, «N. (aquí su nombre) por la gracia de Dios y la Constitución de la Monarquía española, Rey de las Españas; juro por Dios y por los Santos Evangelios que defenderé y conservaré la Religión Católica, Apostólica, Romana, sin permitir otra alguna en el reino: que guardaré y haré guardar la Constitución política y leyes de la Monarquía española, no mirando en cuanto biciere sino al bien y provecho de ella: que no enajenaré, cederé ni desmembraré parte alguna del reino: que no exigiré jamás cantidad alguna de frutos, dinero ni otra cosa, sino las que bubieren decretado las Cortes: que no tomaré jamás a nadie su propiedad y que respetaré sobre todo la libertad política de la Nación, y la personal de cada individuo: y si en lo que he jurado, o parte de ello, lo contrario biciere, no debo ser obedecido; antes aquello en que contraviniere, sea nulo y de ningún valor. Así Dios me ayude, y sea en mi defensa; y si no, me lo demande, ${ }^{5354}$ similar al que debe llevar a cabo el Príncipe de Asturias, llegando a

51 Otra intervención destacada favorable a la modificación del texto propuesto por la Comisión fue la intervención del diputado por Valencia, sacerdote Joaquín Villanueva y Astengo, que legitimó el carácter excluyente, remontándose a los Concilios de Toledo y las condenas que estos hicieran de la «peste del arrianismo».

52 Sólo cabría destacar la intervención de José Miguel Guridy Alcocer, presbítero y diputado por Tlxcala (Nueva España), que no en esta sesión, sino en la del día 25 de agosto, cuando se debatía el artículo primero referente a la Nación española, manifestara que «La unión del Estado consiste en el Gobierno ó en la sujeción á una autoridad soberana, y no requiere de otra unidad. Es compatible con la diversidad de religiones, como se ve en Alemania, Inglaterra, y otros países (...)»

53 Artículo 173.C.E.

54 Esta fórmula de juramento continúa la tradición de las Cortes castellanas, así como el deseo de Carlos IV en el Real Decreto de su abdicación de 8 de mayo de 1808; guarda igualmente 
la edad de catorce años, «N. (aqui el nombre), Principe de Asturias, juro por Dios y por los Santos Evangelios, que defenderé y conservaré la Religión Católica, Apostólica, Romana, sin permitir otra alguna en el reino; que guardaré la Constitución politica de la Monarquía española, y que seré fiel y obediente al Rey. Asi Dios me ayude» ${ }^{55}$.

La presencia no sólo de la religión católica, sino de la institución eclesiástica está presente en las más importantes manifestaciones de los órganos del Estado, así, en el proceso de nombramiento de Diputados de Cortes, ${ }^{56}$ se manifiesta la misma, desde la conformación de las Juntas de Parroquia, ${ }^{57}$ a las que asiste el cura párroco "para dar mayor solemnidad al acto, ${ }^{58}$ que comenzaban con una misa solemne de Espíritu Santo oficiada por el cura párroco, «quien hará un discurso correspondiente a las circunstancias»" y terminaban con un solemne "Te Deum» al que asistían los elegidos, así como los restantes miembros de la misma, ${ }^{60}$ en la fase de Juntas de Partido ${ }^{61}$ se repetía el proceso indicado anteriormente, de tal forma, que una vez concluido el proceso de verificación de poderes, el acto comenzaba en la Iglesia mayor, con una misa solemne de Espíritu Santo, oficiada por el eclesiástico de mayor dignidad «el que hará un discurso propio de las circunstancias; ${ }^{62}$ el acto, al igual que en el caso anterior, finalizaba con la celebración de un «Te Deum.» ${ }^{63}$ En el caso de las Juntas electorales de Provincia, ${ }^{64}$

gran similitud con el artículo 5 del Estatuto de Bayona, aunque éste no contiene en este punto fórmula excluyente. Contiene sin embargo notables diferencias con lo proclamado en el texto francés de 1791, correspondiente al constitucionalismo francés de Monarquía Constitucional, que en su artículo 4, Sección primera del Capítulo II del Título III, en su juramento o fórmula de compromiso omite toda referencia al aspecto religioso.

55 Artículo 212 C.E.

${ }^{56}$ La Constitución de 1812, que proclama el sufragio universal masculino de carácter indirecto, contiene un extenso código electoral, estructurado en cinco capítulos dentro del Título III De las Cortes.

${ }^{57}$ Las juntas electorales de parroquia se componían de todos los ciudadanos avecindados y residentes en el territorio de la parroquia respectiva, incluidos los eclesiásticos regulares (art. 35.C.E.1812), que elegían a pluralidad de votos a los compromisarios, que a su vez nombraban a los electores parroquiales (art. 41), que posteriormente votaban la composición de compromisarios (art.52) que nombraba a los electores de la parroquia (art. 53).

58 Artículo 46 C.E. 1812.

59 Artículos 47 y 48 C.E. 1812.

60 Artículo 58 C.E. 1812

${ }^{61}$ Las Juntas electorales de partido se componían de los electores parroquiales, congregados en la cabeza de cada partido, a fin de nombrar a los electores que habían de concurrir a la capital de la provincia para elegir los diputados de Cortes. Artículo 59 C.E. 1812.

62 Artículos 71 y 72 C.E. 1812.

63 Artículo 77 C.E. 1812.

${ }^{64}$ Las juntas electorales de provincia se componían de los electores de todos los partidos de ella, que se congregaban en la capital a fin de nombrar los diputados que le correspondían para asistir a las Cortes, como representantes de la Nación (art. 78) C.E. 1812. 
se repetía el mismo proceso «En seguida se dirigirán los electores de partido con su presidente a la catedral o iglesia mayor, en donde se cantará una misa solemne de Espíritu Santo, y el obispo, o en su defecto el eclesiástico de mayor dignidad, ${ }^{65}$ hará un discurso propio de las circunstancias, " ${ }^{66}$ finalizaba el acto con la celebración de un Te Deum. ${ }^{67}$

La confesionalidad católica del Estado se pone igualmente de manifiesto en el acto de juramento de los diputados, ${ }^{68}$ «En todos los años el día 25 de febrero se celebrará la última junta preparatoria, en la que se hará por todos los diputados, poniendo la mano sobre los Santos Evangelios, el juramento siguiente: ¿Juráis defender y conservar la Religión Católica, Apostólica, Romana, sin admitir otra alguna en el reino? -R. Sí juro. ¿Juráis guardar y hacer guardar religiosamente la Constitución política de la Monarquía española, sancionada por las Cortes generales y extraordinarias de la Nación en el año de mil ochocientos y doce? —R. Sí juro. ¿Juráis haberos bien y fielmente en el encargo que la Nación os ha encomendado, mirando en todo por el bien y prosperidad de la misma Nación? —R. Sí juro. Si así lo biciereis, Dios os lo premie; y si no, os lo demande».

Aunque desaparece la representación eclesiástica en las Cortes, en cuanto éstas dejan de ser de carácter estamental, desapareciendo por tanto los brazos de la nobleza y las jerarquías de la Iglesia, los miembros del clero gozan de sufragio activo y pasivo, pudiendo por tanto formar parte del Parlamento de carácter unicameral, así en el Discurso Preliminar de la Comisión se manifestaría, «Los nobles y los eclesiásticos de todas las jerarquías pueden ser elegidos en igualdad de condiciones con todos los ciudadanos; pero en el hecho serán siempre preferidos. Los primeros por el influjo que en toda sociedad tienen los bonores, las distinciones y la riqueza; y los segundos, porque a estas circunstancias se unen la santidad y sabiduría tan propias de su ministerio» 6970 .

Respecto al Poder Ejecutivo, que según la división de poderes proclamada en el texto constitucional corresponde al Rey, a cuyo efecto contaba con los correspondientes Secretarios de Estado y del Despacho, así como con el Consejo de Estado, único Consejo del Rey, que éste debía oír su dictamen en los asuntos gra-

${ }^{65}$ Mediante Orden de 7 de septiembre de 1813, se manifestaba que el clérigo de mayor dignidad, en defecto del Obispo, es aquél «que se considere de este modo, con arreglo á los sagrados cánones y estatutos particulares de la catedral ó Iglesia Mayor en que se celebren».

66 Artículo 86 C.E. 1812

67 Artículo 103 C.E. 1812

68 Artículo 117 C.E. 1812

69 Mediante el Decreto CCLXVII de 14 de junio de 1813, se concedía el sufragio activo y pasivo para los regulares secularizados, aunque no para los profesos de las órdenes militares.

${ }^{70}$ Con respecto a las elecciones municipales los eclesiásticos tenían derecho al sufragio activo pero no al pasivo. (Decreto de 21 de septiembre de 1812). 
ves gubernativos, y señaladamente para dar o negar la sanción a las leyes, declarar la guerra, y hacer los tratados, ${ }^{71}$ órgano estatal de especial importancia en un sistema político de carácter unicameral, en el que asumía ciertas funciones correspondientes al Senado, en el mismo, de un total de cuarenta miembros se reservaban cuatro plazas para los eclesiásticos, igual que para los Grandes de España, no pudiendo ser más de este número, en cada caso, «de reconocida y probada ilustración y merecimiento», de los cuáles dos debían ser obispos. ${ }^{72}$

Sin embargo el citado artículo fue ampliamente debatido en las sesiones de los días 30, 31 de octubre y 2 de noviembre de 1811. El motivo de la oposición del sector conservador eclesiástico al artículo se derivaba de los siguientes aspectos:

a) Consideraba exiguo el número de representantes eclesiásticos en el Consejo.

b) Condicionaba la residencia de los Obispos a la pertenencia al Consejo.

c) Atribuía al Consejo funciones en la propuesta de nombramiento de determinados cargos eclesiásticos. ${ }^{73}$

Aunque intervinieron varios diputados por parte del sector eclesiástico conservador, $\mathrm{Dou}^{74}$, que reivindicaba un mayor número de miembros eclesiásticos como consecuencia de su superior preparación intelectual, no sólo en asuntos religiosos, Castillo ${ }^{75}$, que argumentaba su propuesta en los asuntos religiosos que debía tratar el Consejo, para lo que sostenía la mayor formación de los miembros del clero, y sobre todo el Obispo de Calahorra, que con gran vehemencia e indignación llegó a calificar el artículo de injurioso para la Iglesia española, defendiendo la mejor preparación no sólo para asuntos eclesiásticos, sino también de política internacional y relaciones exteriores, incluidas las que debían llevarse con el Vaticano, así mismo defendió que los Obispos no podían abandonar su diócesis en caso de ser nombrados, justificando dicha afirmación en el concilio de Trento. ${ }^{76}$

Estas intervenciones, especialmente la última motivó la de Argüelles, que en nuestra opinión constituye la más radical respecto a las relaciones Iglesia-Estado, de las producidas durante el periodo constituyente, que reproducimos parcialmente:

${ }^{71}$ Artículo 236 C.E. 1812.

72 Artículo 232 C.E. 1812.

73 Art. 237 «Pertenecerá a este consejo hacer al Rey la propuesta por ternas para la presentación de todos los beneficios eclesiásticos, y para la provisión de las plazas de la judicatura».

74 Ramón Lázaro de Dou y Bassols, canónigo y Rector de la Universidad Pontificia de Cervera, diputado por Cataluña

75 Florencio José Castillo; sacerdote y diputado por Costa Rica.

76 Sobre este punto, en la sesión del día 2 de noviembre se produjeron varias intervenciones, D. Antonio Llaneras Amengual, párroco y diputado de Palma, D. José Miguel Ordoa y Barrios, di- 
«El estado eclesiástico no tiene derecho por su instituto á tener parte en el Gobierno. La comisión compuesta por de seis eclesiásticos y de otros individuos á quienes no se les puede tachar de desafectos á aquel estado, no puede desentenderse de la disciplina de la Iglesia. Procedió con mucha circunspección. Aquella repugna que los eclesiásticos se mezclen en los negocios temporales, y solo la conveniencia pública podrá hacer que se haga alguna relajación en la disciplina. Autorizar en la Constitución que los eclesiásticos abandonen las ocupaciones propias de su ministerio para dedicarse á otras profanas, no era de esperar que lo biciese la comisión, ni menos que se le atacase como se ha hecho por su detenimiento y prudencia. Uno de los señores preopinantes quiso alegar que los Prelados eclesiásticos tienen titulo de consejeros; pero hasta abora ¿les ha servido este argumento para quejarse de que no tenían parte en el Consejo de Estado? ... ¿Además, en el Consejo de Estado no se trata de asuntos religiosos, único motivo que pudieran alegar para poder ser llamados. Es preciso no confundir las doctrinas, porque veo, Señor, que lastimosamente y por desgracia se bacen argumentos confundiendo los asuntos de religión con los politicos y de gobierno ¿Qué tiene que ver la religión con el Consejo de Estado, instituido para dirigir la administración pública del Reino? La religión tiene sus pastores establecidos por Dios, y hay una línea divisoria entre ella y el Estado; de manera que jamás se pueden confundir unos negocios con otros.»

La confesionalidad se refleja igualmente en la Administración local, donde «Todos los individuos de los ayuntamientos y de las diputaciones de provincia, al entrar en el ejercicio de sus funciones, prestarán juramento, aquéllos en manos del jefe politico, donde le bubiere, o en su defecto el alcalde que fuere primer nombrado, y éstos en las del jefe superior de la provincia, de guardar la Constitución politica de la Monarquía española, observar las leyes y ser fieles al Rey, y cumplir religiosamente las obligaciones de su cargo.» ${ }^{77}$

En el Poder Judicial, Título V, denominado en el Texto «De los Tribunales y de la Administración de Justicia en lo Civil y Criminal», proclama como corresponde al principio de la división de poderes en el Estado de Derecho, un poder independiente del Poder Ejecutivo y Legislativo, asegurando la independencia e inamovilidad de los jueces, así como el imperio de la ley y la seguridad jurídica; a tal efecto, se procede a la unidad de legislación, poniendo fin a la multiplicidad de fueros, de origen normalmente medieval, existentes en el país ${ }^{78}$; previamente, el 6 de agosto de 1811 se habían suprimido las jurisdicciones señoriales.

putado por Nueva Galicia, que llegaría a ser Obispo de Guadalajara (México), en la que solicitaron que el tema se debía debatir en un Concilio y no en la Constitución.

77 Artículo 337 C.E. 1812.

78 Art. 248. «En los negocios comunes, civiles y criminales no babrá más que un solo fuero para toda clase de personas». 
Sin embargo, en el texto de 1812 no desaparece el Fuero Eclesiástico, «Los eclesiásticos continuarán gozando del fuero de su estado, en los términos que prescriben las leyes o que en adelante prescribieren», ${ }^{79}$ como tampoco desaparece el militar ${ }^{80}$, aunque en este último caso, el fuero se limitaba a causas relacionadas con las obligaciones propias de su estado.

El artículo aprobado correspondiente al Fuero Eclesiástico fue aprobado según la redacción propuestas por la Comisión constitucional, aunque ya en el Discurso Preliminar podemos observar ciertas reticencias al respecto, en las que se manifiesta su permanencia, que debemos entender como consecuencia de la proclamación de la confesionalidad del Estado y la importancia de la institución eclesiástica en el país, pero al mismo tiempo, la Comisión incide en la falta de argumentación histórica que justifique se existencia. «La Comisión ha creído al mismo tiempo que no debía hacerse alteración en el fuero de los clérigos hasta que las dos autoridades civil y eclesiástica arreglasen este punto conforme al verdadero espiritu de la disciplina de la Iglesia española, y a lo que exige el bien general del reino; no obstante que en el Fuero Juzgo era desconocida la exención de litigar y ser reconvenidos o acusados los eclesiásticos en los negocios comunes, civiles $y$ criminales ante los jueces $y$ tribunales ordinarios. ${ }^{81}$

No obstante, el Supremo Tribunal de Justicia conocía de todos los recursos de fuerza de todos los tribunales eclesiásticos superiores de la Corte. ${ }^{82}$

El debate sobre el Fuero el 15 de noviembre, dio lugar a una de las más amplias discusiones habidas en todo el proceso constituyente, aunque menor que el que la Cámara dedicara al Fuero Militar. En la opinión que sostenemos, la importancia del debate se caracteriza, no tanto por los diferentes criterios, percibidos desde la primera sesión de Cortes entre los representantes del sector liberal y los conservadores, sino por ser la primera vez que el sector liberal se encuentra dividido en dos facciones, una representada por la Comisión y sus defensores, partidaria de la aprobación del artículo citado, de carácter posibilista y pragmático, cuyo máximo representante sería Agustín de Argüelles, que en esta ocasión se van a alinear con el sector eclesiástico y conservador, y otra de carácter más rupturista, partidaria de la plena extinción del Fuero, representada por los diputados Calatrava, ${ }^{83}$ Conde de Toreno ${ }^{84}$ y García Herreros. ${ }^{85}$

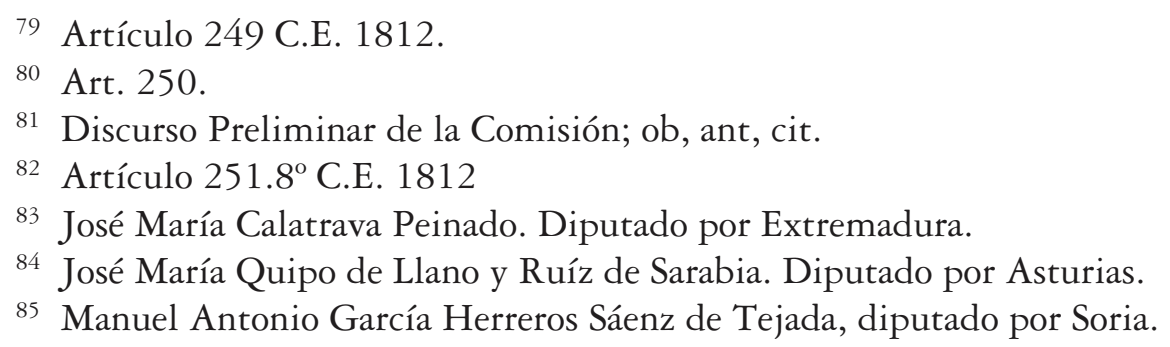


El argumento fundamental sostenido por el grupo contrario al Fuero, se encuentra en la intervención de Calatrava en la sesión del 16 noviembre, en la que manifiesta que no entiende que tras la limitación del Fuero Militar, no se haga lo mismo con el Eclesiástico, ya que igual que en el caso de los militares, en la actuación de los eclesiásticos, debe separarse su actuación como ciudadanos comunes de la que tienen en el ejercicio de su profesión, «(...) porque reconozco que la Iglesia debe entender en aquellas cosas que le son peculiares, y en las actuaciones de sus ministros como tales eclesiásticos. Pero en los asuntos puramente temporales, en las acciones de los clérigos como ciudadanos, en un contrato, no sé, repito, cómo la comisión ha querido conservarles el Fuero».

Por su parte, el sector conservador, que no era partidario de la puerta abierta que el artículo dejaba para una futura modificación del Fuero, pero que mantenía la propuesta de la Comisión como mal menor, defendió la existencia del Fuero, en algún caso, Sr. Dou, por entender que la unicidad de fueros, podría propiciar la «pérdida de la libertad», aspecto que argumenta que el poder pudiera estar detentado por un solo grupo o partido, poniendo a este respecto ejemplos del mundo romano, e incluso el principio de la división de poderes de Montesquieu; en otros casos, el argumento sostenido era el origen divino del Fuero Eclesiástico y del «derecho de una posesión más que inmemorial» (Sr. Guereña) y que por tanto sólo podía ser modificada por un Concilio, aspectos en lo que incide el Obispo de Calahorra, «(...) debo decir que la inmunidad de los ministros sagrado reconoce su origen y fundamento en el derecho divino; que así se ha reconocido en todos tiempos», así mismo, el citado diputado eclesiástico, manifiesta como amenaza, que en caso de supresión del fuero, las consecuencias serían peores, ya los inculpados podrían ser objeto de las más duras sanciones canónicas, «Por último, que si se quiere remediar lo que se contempla exceso en el uso de de las facultades de los Prelados de la Iglesia, debe también moderarse el que se ha introducido en los magistrados civiles; y si no reponiéndose los Obispos en sus derechos, dados por el mismo Jesucristo y su Iglesia, y ejercidos inconcusamente, usarán de la espada de la excomunión y demás censuras, impondrán penitencias públicas de siete, diez y más años á los delincuentes, haciéndolos pasar por las estaciones tan sabidas en la bistoria eclesiástica, lo que en realidad será más doloroso y aflictivo para los fieles».

El sector liberal contrario a la permanencia del fuero en el texto constitucional, no discutió el origen divino del Fuero en lo que respecta a los asuntos eclesiásticos, negándolo en otros aspectos, en los que sostenía que el mismo era consecuencia de cesión del poder real, y que por tanto, el poder temporal podía revocarlo cuando quisiera «Así pues, mediante que el fuero de los eclesiásticos en Espa$\tilde{n} a$, desconocido en nuestro primer Código (Fuero Juzgo), no ha debido su origen sino á la generosidad de los Reyes, V.M. tiene legítima autoridad para revocar esa gracia, ó para reducirla á sus justos límites, y debe bacerlo porque el interés de la Nación consiste en que no 
haya tales fueros» ${ }^{86}$ (Calatrava), argumentando su supresión en el desarrollo del principio de igualdad proclamado en la Constitución «(...) Y ¿cómo podrá ser igual si existen privilegios que al tiempo que favorecen á unos dañan y perjudican á los demás?» (Conde de Toreno).

En defensa de la Comisión intervino el diputado Villanueva, que alguna forma expresa el pensamiento de los liberales posibilistas, admitir el Fuero, esperando que en un tiempo futuro el mismo pueda ser modificado, «Por lo mismo, apruebo el artículo como está; y no dudo que la indicación que en él se bace de las leyes con que conviene rectificar el uso del fuero, excitará el celo de la autoridad civil y eclesiástica, á que en tiempos más tranquilos cumplan en esta parte lo que desea la comisión en obsequio del Estado y de la misma Iglesia».

El artículo fue aprobado el 17 de noviembre de 1811.

La confesionalidad del estado se manifiesta igualmente en el Título IX, dedicado a la Instrucción Pública, de tal forma, que proclama, que junto a la enseñanza de las primeras letras que se enseñarán en las escuelas de todos los pueblos, se impartirá «el catecismo de la religión cristiana, ${ }^{87}$ en todo caso, aunque se pretende que la enseñanza tenga un carácter nacional, controlada por el Estado, «las ciencias sagradas y morales continuarán enseñándose según los dogmas de nuestra santa religión y la disciplina de la iglesia en España. ${ }^{88}$

La confesionalidad católica del sistema político nacido en Cádiz vuelve a ponerse de manifiesto, con motivo del acto de la firma y juramento de la Constitución por los diputados, acto para el que se establece que en la fórmula de juramento de los mismos, se dirá "¿Juráis por Dios y por los santos evangelios, que defenderéis y conservaréis la religión católica, apostólica romana sin permitir otra alguna vez en el reyno. $(. . .)^{89}$, así mismo, se proclama, que a continuación «se celebrará una misa solemne de acción de gracias, y después se cantará el Te Deum» ${ }^{90}$; protocolo que se manda repita en todos los pueblos de la Monarquía cuando se de a conocer el nuevo texto constitucional, «En el primer día festivo inmediato se reunirán los vecinos en su respectiva parroquia, asistiendo el juez y el ayuntamiento, (...) se celebrará una misa solemne de acción de gracias. Se leerá la Constitución antes del ofertorio: se hará por el cura párroco, ó por el que este designe, una breve exhortación correspondiente al objeto; después de

86 Alguna intervención en defensa de la supresión de esta concesión temporal, revistió un punto de acritud «Sean enhorabuena acreedores de las exenciones que disfrutan; pero no incurran en la ingratitud de desconocer la mano que los beneficia para convertir en independencia lo que es pura gracia;» (García Herreros) lo que propició una protesta por parte del sector más conservador.

87 Artículo 366 CE. 1812.

${ }^{88}$ Discurso Preliminar de la Comisión; ob, ant,cit.

89 Decreto CXXXVII. Art. III.

90 Artículo IV. 
concluida la misa, se prestará juramento por todos los vecinos y el clero guardar la Constitución baxo la fórmula siguiente: ¿Juráis por Dios y por los Santos Evangelios guardar la Constitución política... y se cantará el Te Deum» ${ }^{91}$. Similar procedimiento se manda seguir a todas las autoridades del Reino, incluidos los M.RR Arzobispos, RR Obispos, Prelados, Cabildos Eclesiásticos y Comunidades Religiosas, mandando que en todas las Catedrales, colegiatas, universidades y comunidades religiosas se «celebrará una misa de acción de gracias con Te Deum, después de haber jurado los respectivos cabildos y comunidades la Constitución» ${ }^{92,93}$.

\section{LA LEGISLACION PRODUCIDA REFERENTE A ASUNTOS RELACIONADOS CON LA IGLESIA}

Es muy abundante la legislación de las Cortes tanto en las de carácter extraordinario, como las ordinarias, referentes a asuntos relacionados con la Iglesia católica; muchas de ellas, ya han sido citadas en epígrafes anteriores del presente trabajo, por lo que procederemos a su omisión.

Procede ahora resaltar aquellos Decretos y Órdenes más representativos de la actuación de las Cortes.

Podemos agrupar su actuación en los siguientes apartados:

a) De carácter económico.

b) Abolición del Tribunal del Santo Oficio.

Podría añadirse un tercer apartado referente al tratamiento legislativo o amplios debates en Cortes sobre asuntos internos de la Iglesia, tales como la celebración de un Concilium nacional, la provisión de curatos y otras plazas eclesiásticas, tratamiento de régimen interno, etc; no obstante, debemos considerar que tal aspecto se nos presenta como de muy escaso interés para el objeto del presente trabajo, aunque sí es muy representativo de la sensibilidad de las Cortes sobre el tema religioso.

\section{A) De carácter económico.}

Sobre este punto, debemos destacar dos aspectos diferentes:

91 Decreto CXXXIX de 18 de marzo de 1812, Art. I.

92 Artículo III. Este acto religioso, mediante el decreto CCXXXIV se repetiría todos los años en el aniversario del 19 de marzo.

93 Sobre la práctica extendida de las Cortes de ordenar este tipo de oficio religioso, cabe destacar, a modo de anécdota, que mediante el decreto CCXXI de 16 de febrero de 1813, ordenaba su celebración en toda España, por el triunfo del emperador de Rusia sobre las tropas napoleónicas. 
a) Medidas de carácter estructural y reformista.

b) Medidas de tipo coyuntural.

\section{a) Medidas de carácter estructural y reformista}

Respecto a las primeras, hay que tener presente, que la Constitución de 1812, como texto correspondiente al primer Estado Liberal, tiene como objetivo, casi prioritario, poner fin al Antiguo Régimen, poniendo fin a la sociedad estamental y creando condiciones para el desarrollo de la sociedad de clases; a tal efecto, como ya ocurriera con los textos norteamericano y francés, pondrá especial atención en salvaguardar el principio de propiedad ${ }^{94}$, pero entendida ésta como un derecho de carácter individual y no institucional; en este sentido, su reforma de la propiedad afectará tanto a la Iglesia, como a otras organizaciones de carácter público, sean estatales, como municipales o de otras corporaciones privadas. Al mismo tiempo intentará poner fin a las formas de propiedad de origen, normalmente medieval, que llevaban aparejadas otras formas de dominio sobre personas y municipios.

En este primer intento correspondiente al primer Estado de Derecho, los liberales españoles eran conscientes de las diferencias existentes entre el caso español y las experiencias habidas anteriormente en Estados Unidos y Francia, especialmente en lo referente a las estructuras económicas y sociales, y dentro de éstas, al diferente peso de la religión en los estados citados; es por ello que nunca se dará una batalla frontal, ni siquiera un planteamiento diáfano en aspectos como la proclamación de la separación de la Iglesia y el Estado; por el contrario, los liberales españoles se van a limitar a sostener los principios de unidad jurisdiccional, sistema contributivo único estatal o local, derecho de propiedad exento de señoríos jurisdiccionales o sujetos a prácticas medievales etc. En virtud de que estas medidas choquen con los intereses eclesiásticos, se producirá un ámbito de conflicto con la Iglesia, pero en todo caso, no se podrá decir que iban dirigidas específicamente contra la misma. No obstante, es evidente que muchas de las mismas tenderán a disminuir el poder temporal de de la Iglesia, pero no más que el objetivo de las políticas regalistas seguidas durante el siglo XVIII en Francia, o incluso en España durante los reinados de Carlos III y Carlos IV, aunque en el caso español, a diferencia de Francia, el resultado no se viera coronado con el éxito.

Por tanto, muchas de las medidas que las Cortes proclamarán debemos situarlas históricamente como de un regalismo tardío, que intenta sobreponer la

${ }^{4}$ El Decreto LXXXII de 6 de agosto de 1811, en su artículo IV, califica el derecho de propiedad como sagrado. 
autoridad del Estado sobre la jerarquía católica, así como disminuir la influencia vaticana sobre la iglesia española.

\section{Abolición del Voto de Santiago 95.}

Mediante el Decreto CCIII de 14 de octubre de 1812, se abolía el Voto de Santiago ${ }^{96}$, poniendo fin a una vieja demanda de numerosos pueblos españoles que debían satisfacer este tributo para la catedral de Santiago de Compostela. Previamente, mediante la Orden de $1^{\circ}$ de septiembre de 1812 , se había declarado extinguido el fuero privilegiado del Voto de Santiago, "Que con arreglo á la misma Constitución queda extinguido el fuero privilegiado del Voto de Santiago, y que en consecuencia deben conocer de él los jueces de primera instancia». Ello se hace tras la sesión de Cortes del mismo día ${ }^{97}$, tras la propuesta de su abolición que hiciera el diputado Alonso López y Noball ${ }^{98}$, lo que dio lugar a un debate en el que se enfrentarían las posturas de liberales y conservadores eclesiásticos, por la parte liberal las argumentaciones eran, primero de falsedad histórica del origen del impuesto, «este pergamino apócrifo en su origen, ridículo en su relación, falso en su data y pernicioso en sus efectos» (Villanueva), «tributo ilegítimo en su origen», que diría Argüelles y segundo la vulneración del principio de igualdad de los españoles y la necesidad de unificar las contribuciones de los ciudadanos (Conde de Toreno).

La defensa del mantenimiento del denominado Voto de Santiago estuvo a cargo del diputado Blas de Ostolaza ${ }^{99}$, que defendió la veracidad histórica del asunto, considerando que cuestionar la presencia del Apóstol Santiago en España era una actitud antirreligiosa y antipatriótica, y fundamentalmente el Obispo de Orihuela Simón López, que defendió que se trataba de un asunto perteneciente a la esfera espiritual y no podía ser objeto de la atención de las Cortes, ya que en su resolución era obligada la consulta a la Catedral de Santiago, los Obispos e incluso el Papa; otros diputados coincidían con que tampoco el tema

95 El Voto de Santiago era un tributo, de oscuro origen medieval, similar al diezmo, que se justificaba en la intervención del Apóstol Santiago en la batalla de Clavijo, al principio sólo afectaba a Galicia, aunque posteriormente los Reyes Católicos lo extenderían por todo el país, era muy impopular y su impago acarreaba pena de excomunión. Sobre este punto, véase García León, José María (2002); «La abolición del Voto de Santiago en las Cortes de Cádiz»; Revista de Estudios Regionales, $n^{\circ} 64$.

96 El gobierno de José I, mediante Decreto de 21 de agosto de 1809, suprimió el voto de Santiago.

${ }_{97}$ Las sesiones de Cortes se desarrollaron los días 12, 13 y 14 de octubre de 1812.

98 José Alonso López y Nobal, diputado por Galicia.

99 Blas Gregorio Ostolaza y Ríos. Diputado por Trujillo (Perú). 
debía resolverse en las Cortes, sino en los Tribunales (Sr. Borrull $)^{100}$. Sometido a votación con la ausencia de varios Obispos diputados, el resultado fue de 85 votos a favor de la abolición y 26 en contra ${ }^{101}$.

Decreto LXXXII, que ponía fin a los señoríos jurisdiccionales, incorporándolos a la Nación. El Decreto, aunque no iba dirigido específicamente contra propiedades de la Iglesia, sí afectaba a parte de su patrimonio; sobre este Decreto la jerarquía eclesiástica española argumentaría para su no cumplimiento, que dichas propiedades, en su caso, no podían considerarse personales, sino adjuntas a la dignidad arzobispal u obispal correspondiente, por lo tanto, estaban inmersas en los derechos de la Iglesia.

Decreto CLXXV de 17 de junio de 1812, por la que el Estado se apropiaba de los bienes «de cualquier clase que sean, pertenezcan á establecimientos públicos, cuerpos seculares, eclesiásticos ó religiosos de ambos sexos, disueltos, extinguidos ó reformados por resultas de la invasión enemiga, ó por providencias del gobierno intruso...»; aunque tal mandato, podía considerarse de carácter temporal y derivado de la urgencia de la situación económica de la Nación, debe resaltarse, que venía a legitimar la medida tomada por José I al respecto, además, si consideramos la orden de Hacienda del mes de agosto, que ordenaba cerrar los conventos que hubieran sido disueltos por el gobierno intruso, podía tornarse en definitiva, especialmente si consideramos las duras condiciones proclamadas en los decretos posteriores CCXXII de 18 de febrero de 1813 y CCLXXXVII de 26 de agosto de 1813, sobre el restablecimiento de Casas y Conventos religiosos, en los que se exigía que los mismos no estuvieran destruidos, tuvieran al menos 12 miembros y sólo existiera uno en cada pueblo.

Decreto CCXXVI de 22 de febrero de 1813, por el que se declaraban nacionales los bienes que fueron de la Inquisición, así como de las fundaciones, patronatos, cofradías o hermandades que hubieran estado bajo su protección (art. IX).

\section{b) Medidas de tipo coyuntural.}

Los gastos derivados de la guerra obligaron a tomar medidas extraordinarias de carácter recaudatorio, entre ellas varias referentes al patrimonio de la Iglesia; gran número de estas medidas se proclamaron en época anterior al periodo constituyente, aunque posteriormente fueron desarrolladas por las Cortes mediante Decretos Órdenes y Reglamentos.

100 Francisco Xavier Borrull y Vilanova. Diputado por Valencia.

101 Restablecido el Voto de Santiago con el retorno al absolutismo, fue de nuevo bajo la vigencia de la constitución de 1812, durante el Trienio Liberal, que el tres de abril de 1820, fue de nuevo abolido, aunque sólo lo fuera definitivamente el tres de octubre de 1834, a petición de los liberales doceañistas en el Estamento de Próceres durante la vigencia del Estatuto Real. 
Entre otros, podemos destacar el Decreto LII de $1^{\circ}$ de abril de 1811 , de contribución extraordinaria a la guerra, aunque el mismo no iba dirigido a la iglesia, sí afectó a sus propiedades, en cuanto en su desarrollo se refería a la institución eclesiástica y a sus miembros, desarrolló los Decretos de la Junta Central de 6 de diciembre de 1809, que mandaba aplicar las obras pías a las urgencias del Estado, salvo las referentes a hospicios, hospitales etc, y 12 de enero de 1810.El reglamento de verificación de dicho Decreto es de 3 de septiembre de 1812.

Decreto LXV, de 8 de mayo de 1811 que desarrolla el decreto de 6 de noviembre de 1808 de la Junta Central para recoger el oro y la plata de la Iglesia, y que ésta sea destinada al socorro de las urgencias del Estado.

Decreto XVI de 1 de diciembre de 1810, sobre suspensión de prebendas y algunas otras piezas eclesiásticas para atender con sus rentas a las urgencias del Estado, prohibiendo a los Arzobispos, Obispos, Cabildos, Comunidades, Patronos particulares eclesiásticos o laicales, procedan a hacer nombramiento alguno en las piezas eclesiásticas y beneficios o prebendas y que tal dinero se incorpore a la tesorería real. Dicho Decreto se desarrollaría mediante Orden del 17 de abril de 1811, con el fin de que el mismo fuera ejecutado por las Juntas Provinciales, así como por el Decreto LIX de 20 de abril de 1811, que indica se aplique al erario público el producto de los beneficios procedentes de expolios y vacantes, así como parte de las pensiones eclesiásticas.

Orden de 28 de agosto de 1811 por la que se declara sujeta a contribución extraordinaria de guerra la parte que corresponda a los bienes decimales.

El 3 septiembre de 1812 tendría lugar el Decreto CXC, que incide directamente en las rentas y propiedades del clero directamente «Los M.RR. Arzobispos y RR. Obispos pasarán al ayuntamiento del pueblo en que residan, relaciones firmadas en los términos prescritos, de las rentas y utilidades líquidas que disfruten por qualquier título, expresando en las mismas con separación las que procedan de sus mitras, y las de sus bienes y derechos particulares (Art. IV). Similar para los cabildos y corporaciones eclesiásticas, incluidas rentas personales de sus miembros (arts. V y VI), así como para los eclesiásticos seculares (art. VII) y, prelados de los monasterios y conventos (VII), prelados provinciales y comarcales (I)X, Cofradías, hermandades (XI)...»

Cabe destacar igualmente, por su contenido peculiar el Decreto CXCI de 15 de septiembre de 1812, referente a la tasa de los sumarios de la bula de la santa cruzada, por el que el Estado se apropiaba de unos ingresos tradicionalmente exclusivos de la Iglesia. ${ }^{102}$

${ }^{102}$ Las Cortes generales y extraordinarias, enteradas de que la santidad del Papa Pio VI, atendiendo a los grandes gastos que continuamente se hacen en defensa de la Santa Fé Católica, prorrogó a esta monarquía la gracia de la bula de la santa cruzada de Vivos, difuntos, composición y-Lactinicios por veinte años ...y 


\section{B) Abolición de la Inquisición. ${ }^{103}$}

Mediante el Decreto CCXXIII de 22 de febrero de 1813 se abolía la Inquisición ${ }^{104}$, poniendo fin en España a una institución que se había mantenido desde la bula de Sixto IV de noviembre de $1478^{105}$ y que había llegado a tener un inmenso poder dentro de la Corona, pudiendo ser considerada como un Estado dentro del Estado ${ }^{106}$. De esta forma, se ponía fin a un viejo deseo no sólo de los liberales españoles, sino de la política regalista de la Corona española del siglo XVIII, que si bien no puede afirmarse plenamente que quisieran poner fin a esta institución secular, sí es cierto que habían pretendido disminuir las

con la condición de que si concluido el término último de los veinte años se ballase interceptada la comunicación de la Santa Sede, se habia de durar esta prórroga tanto tiempo como la incomunicación... (se prorroga) el Indulto Apostólico Quadragesimal, en virtud del qual pueden tomar los fieles de ambos sexos comer carnes en los días de vigilia no exceptuados, baxo la regulación de la limosna que por cada Sumario de todas clases biciese el Comisario general de la Cruzada...» A continuación especifica las tasas correspondientes a cada una de las regiones del país.

103 Sobre este punto véase Núñez Rivero; «La cuestión religiosa en las cortes de Cádiz»;ob,ant, cit.

104 El Gobierno bonapartista, mediante un Decreto firmado por el Emperador Napoleón Bonaparte y refrendado por Huges B.Maret, Ministro Secretario de Estado, había suprimido el Tribunal del Santo Oficio en España, el 4 de diciembre de 1808, en la localidad Chamartín, próxima a Madrid. «en nuestro campo Imperial de Madrid»; el decreto fue publicado en la Gazeta del doce del mismo mes.

${ }^{105}$ Loa primeros inquisidores: Juan de San Martín y Miguel de Morillo, fueron designados el 27 de septiembre de 1480; sobre este punto y en general sobre la actuación del Tribunal del Santo Oficio en España, véase Kamen, H; «La Inquisición española»; Ed. Crítica 1999.

106 A este respecto, deben recordarse los intentos, en parte fracasados, del rey Carlos III por imponer la autoridad real sobre el citado Tribunal, como consecuencia de la política «regalista» que intentara implantar dicho monarca, que ya puso en marcha con cierto éxito en el Reino de Nápoles; sin embargo, la realidad le demostraría que la importancia de la iglesia era muy desigual en los dos Reinos, así como lo era el arraigo popular de la Inquisición. No obstante, cabe destacar que en 1762 Carlos III sostuvo un duro enfrentamiento con el Santo Oficio y con el Papado, (Clemente XIII) como consecuencia de la aplicación del regium execuator, (pase regio) que proclamaba la autoridad real sobre la de la iglesia en determinados asuntos de gobierno; el motivo fue la petición real de que el catecismo «La exposición de la doctrina cristiana» del teólogo francés Messenguy, fuera excluida del «Índice de Libros probibidos», conflicto que acarreó la expulsión por orden real del Inquisidor General, Manuel Quintano Bonifaz; asimismo, como contrapartida a esta política real fueron condenados por el Tribunal importantes colaboradores de Carlos III, entre los que cabe destacar especialmente a Rafael Melchor de Macanaz, teórico del regalismo, al ministro Olavide, que fue condenado por hereje, Jovellanos, objeto de un Auto de Fe, así como otros amenazados, caso de Campomanes. Conde de Floridablanca, Aranda etc y numerosos periodistas de la entonces incipiente prensa española, entre los que debe destacarse a García Cañuelo («El Censor»), Clavijo y Fajardo ( El pensador»), a los que se les hizo abjurar de levi, con estas condenas, lo que la Inquisición intentaba era delimitar las pretensiones del regalismo regio 
atribuciones de la misma y ejercer un mayor control del Estado sobre el Tribunal. ${ }^{107}$

El debate que tuvo lugar en las Cortes de Cádiz referente a la supresión del Tribunal del Santo Oficio, fue uno de los más arduos en la historia de la Cámara, dando lugar como indica el historiador Cuenca Toribio ${ }^{108}$ a la más extensa y áspera polémica de las numerosas que tuvieron como escenario el Cádiz de las Cortes. El resultado de la votación, 90 votos a favor y 60 en contra, demuestra lo reñido del debate, en un tema de una importancia tan a flor de piel, como era en aquel momento la cuestión para los representantes de la Nación española, ${ }^{109}$ y que como ninguno otro supo representar el enfrentamiento existente entre los sectores liberales y conservadores eclesiásticos.

El Decreto, en cuya exposición de motivos se indica que es consecuencia del artículo 12 de la Constitución, proclama en su artículo 1 del Capítulo I, que «La Religión Católica, Apostólica, Romana será protegida por leyes conformes a la Constitución», añadiendo en su artículo II, que «El Tribunal de la Inquisición es incompati-

107 Mediante Real cédula de 18 de agosto de 1763 se quitaba el privilegio de fuero a los familiares del Santo Oficio, inculpados en delitos de orden público, quedando sometidos a la jurisdicción ordinaria; el Real Decreto de 20 de noviembre de 1767 suprimía la exención de pago de impuestos extraordinarios que antes favorecía los ingresos no procedentes del salario de los ministros del Santo Oficio; la Real cédula de 2 de febrero de 1770 atribuía en exclusividad a la Justicia de la Corona las competencias en los delitos de bigamia, sodomía o blasfemia; En realidad, lo que se pretende en el último tercio del siglo XVIII es asentar el principio de «regalía», intentando disminuir el poder del Santo Oficio, bien mediante la asunción real de atribuciones al efecto o mediante el hecho de que numerosas causas entendidas por el Tribunal pasaran a ser competencia de los Obispados; este aspecto se reforzaría tras los acontecimientos revolucionarios franceses, en los que para su control y censura no se consideraba que los miembros de la inquisición contaran con la preparación suficiente, así como indicara Jovellanos en su informe sobre el Tribunal presentado al Rey Carlos IV «que ignoran las lenguas extrañas, que solo saben un poco de teología escolástica y de moral casuística»; Véase al respecto, Núñez Rivero, Cayetano; «Iglesia y Religión en el periodo isabelino 18331868»El libro Homenaje a Jorge de Esteban (en prensa); véase igualmente Elorza, Antonio; «La Inquisición y el pensamiento ilustrado»; Historia 16. 1986; Moreno Martínez, Doris; «Representación y realidad de la inquisición en Cataluña»; UAB. Barcelona 2002.

108 José Manuel Cuenca Toribio «Las últimas hogueras»; En La Inquisición; Historia 16. Madrid. 1976, pag. 97.

109 No obstante lo indicado, la mayoría de los historiadores coinciden en que el debate parlamentario, que tampoco tuvo una gran altura dialéctica, aunque sí un alto contenido ideológico, no fue seguido con el mismo interés por la mayoría de la población española, lo que no obsta, para que se publicaran numerosos folletos en su mayor parte anónimos en la ciudad de Cádiz, a favor y en contra del Tribunal del Santo Oficio; valga destacar entre los detractores del Tribunal a Natanael Jamtob (seudónimo de Antonio Puigblanch), que publicó el libro «La Inquisición sin máscara», y entre sus defensores al dominico Fray Francisco Alvarado, que publicó «El filósofo rancio». 
ble con la Constitución». En consecuencia, la protección de la iglesia, se encomendaba a los Obispos y sus Vicarios en las causas de Fe, con arreglo a los Cánones y Derecho Común, ${ }^{110}$ y a los jueces seculares para declarar e imponer a «los herejes» las penas que señalan las leyes; en todo caso, los jueces eclesiásticos, y seculares debían proceder en sus respectivos casos conforme a la Constitución y las leyes. ${ }^{111}$ En virtud del Decreto, no desaparecían por tanto los delitos contra la iglesia, sino que simplemente los mismos, cuando fueran acreedores a pena mayor a la de amonestación, ${ }^{112}$ el juez eclesiástico debía pasar testimonio del sumario al juez respectivo para su arresto, y éste le tendría a disposición del juez eclesiástico para las demás diligencias hasta la conclusión de la causa, y fenecida la misma, se pasaría el reo al juez civil ${ }^{113}$ para la declaración e imposición de la pena. ${ }^{114}$

El Decreto, garantiza a la Iglesia el control de los libros importados o que se publiquen en el reino, «El Rey tomará todas las medidas convenientes para que no se introduzcan en el reyno por las aduanas maritimas y fronterizas, libros ni escritos probibidos, ó que sean contrarios á la Religión; sujetándose los que circulen á las disposiciones siguientes, y á las de la ley de la libertad de imprenta.» ${ }^{115}$ El procedimiento, que de hecho equivalía a una censura previa a la publicación, consistía en que el Obispo podía negar la licencia de impresión a los escritos sobre religión, o que entendiera iban contra la misma, aunque debía dar audiencia antes al interesado; posteriormente, el juez secular, procedía a recoger dichas publicaciones o escritos prohibidas por el Ordinario, o que se hubieran publicado sin la correspondiente licencia, ${ }^{116}$ aunque los autores podían apelar al juez eclesiástico. ${ }^{117}$ La relación de libros prohibidos era remitida por los jueces eclesiásticos a la Secretaría de Gobernación, que a su vez, la pasaba al Consejo de Estado, para que después de haber oído el parecer de una «junta de personas ilustradas», expusiera su dictamen, que posteriormente, el Rey, con la aprobación de las Cortes, mandará publicar, y «será guardada en toda la Monarquía como ley, bajo las penas establecidas» ${ }^{118}$.

Podemos resumir las opiniones vertidas en el debate en las siguientes:

110 De esta forma, se restablecía en su primitivo vigor la ley II, título XXVI, Partida VII.

111 Artículo II; Capítulo I.

112 Si el delito sólo era merecedor de amonestación, ésta sería llevada a cabo por el juez eclesiástico, que lo hará, en los términos previstos en la ley de Partidas. (Artículo II Capítulo I.).

113 En el caso de que el acusado fuera eclesiástico secular o regular, procederá por sí al arresto el juez eclesiástico.

114 Artículos V y IX. Capítulo I.

115 Artículo I; Capítulo II.

116 Artículo II; Capítulo II.

117 Artículo III; Capítulo II.

118 Artículos IV y V Capítulo II. 
A favor del mantenimiento de la Inquisición:

a) El Tribunal del Santo Oficio no puede considerarse como una institución creada por el Poder Real español, sino que es consecuencia de la autoridad Pontificia, por lo que corresponde a ésta su posible supresión, sin que pueda ser eliminado de forma unilateral por parte española.; en este argumento incidiría especialmente el representante de los Estados Vaticanos, Nuncio Pedro Gravina, defensor de que sólo el Papa podía suspender el funcionamiento del Tribunal.

b) El Tribunal de la Inquisición, en virtud del acendrado catolicismo existente en la sociedad española, elemento fundamental de la unidad de la Nación, había desempeñado durante siglos el papel de guardián de la fe y de los principios católicos, velando de esta forma por la unidad de la comunidad hispana y la vertebración de la misma. ${ }^{119}$

A favor de la abolición del Tribunal de la Inquisición.

a) La existencia del Tribunal de la Inquisición era incompatible con la Constitución de 1812 y los principios proclamados en la misma, tanto en lo que respecta a la libertad de expresión e imprenta proclamado en 371, como en la abolición del tormento (art. 303), así como en los restantes derechos individuales proclamados fundamentalmente en el Capítulo III del Título V, Artículos 266 a 308.C.E. 1812, referentes a las garantías de los detenidos y el funcionamiento de la Administración de Justicia.

b) El Tribunal de la Inquisición, representaba mejor que ninguna otra institución, la estructura política y social del Antiguo Régimen, siendo una de las causas más importantes del atraso social y económico de la sociedad española ${ }^{120}$; por otra parte, significaba el reconocimiento de un sta-

119 Respecto a la contribución a la vertebración de la Nación, que había significado la Inquisición española, se abrió un debate intenso y agrio, en el que defensores y detractores incurrieron en todo tipo de excesos verbales, valga como muestra la intervención del fraile Antonio Ruiz de Padrón, Diputado por Canarias, «Cómo es que España guardó intacta su fe desde la abjuración del arrianismo, en tiempos del católico Recaredo, hasta el del establecimiento de la Inquisición?, ¿Cómo es que nuestros padres, mezclados por muchos siglos con los judios y sarracenos, conservaron inmaculada su religión sin el puntal de la Inquisición? (...) Hablando expresamente con los fariseos (Dios) les dice en su evangelio: quiero la misericordia y no el sacrificio; Misericordiam volo et non sacrificium. Pero la Inquisición quiere el sacrificio y el sacrificio más cruento... Los sanos dice el Señor, no necesitan de médico, sino los enfermos. En efecto, los herejes necesitan de medicinas... Pero ¿qué medicinas les aplica la Inquisición? ¿Son, por ventura, la predicación, la persuasión, la paciencia, la caridad, que son las medicinas del evangelio, o les aplica azotes, cadenas, grillos, garruchas, torturas y fuego».

${ }^{120}$ La argumentación más rotunda respecto a que el Tribunal de la Inquisición representaba el atraso de la Nación en los aspectos económicos, sociales, culturales, y causa de casi todos los males que la aquejaban, podemos encontrarlos en el diputado citado anteriormente «Tírese una rápi 
tus eclesiástico de carácter estamental, incompatible con el Estado de Derecho.

Sobre el primer punto indicado referente a que la supresión de la Inquisición no podía ser un acto unilateral del Estado español, sino que correspondía a la Santa Sede, cabe destacar la actitud del Nuncio de su Santidad Pedro Gravina, que elevó una airada protesta ante las Cortes el 5 de marzo, tras la promulgación del Decreto de disolución del Tribunal, en la que solicitaba se declarase nulo dicho acto, por perjudicar grandemente a los intereses de la Santa Sede, y que fuese suspendido el mismo hasta el final de la guerra, actitud que fue defendida por el Cabildo gaditano, y que fue apoyada por un importante número de autoridades eclesiásticas; ${ }^{121}$ la actitud del Nuncio, seguida por la del Cabildo de Cádiz y otras autoridades eclesiásticas, fue apoyada en principio por la Regencia, compuesta entonces por el Duque del Infantado, Mosqueras, Villavicencio, Rodríguez de Rivas y Pérez Villamil, a lo que las Cortes respondieron declarándose en sesión permanente; Agustín de Argüelles propuso la destitución de los miembros de la Regencia y su sustitución por otra formada por el Arzobispo de Toledo, Luís María de Borbón, tío del Rey, Cicar y Agar; la nueva Regencia hizo cumplir los decretos de las Cortes. Y expulsó al Nuncio Gravina del país ${ }^{122}$ «(...) ha faltado a las leyes de su legación, al respeto debido al Congreso Nacional y a la confianza con que le abriga en su seno un reino católico... Lo que no permitiré jamás en ningún prelado español, mucho menos debo tolerarlo en un extranjero que no corresponde a la bospitalidad $y$ a la generosidad de los españoles». ${ }^{123}$

En virtud de la oposición que suscitó la elaboración del citado decreto entre la mayor parte del estamento eclesiásticos, que se negaron a su cumplimiento como se ha indicado anteriormente, las Cortes procedieron a publicar otro, que

da ojeada sobre la faz de la península después del establecimiento de la Inquisición, y se verá que desde aquella desgraciada época desaparecieron de entre nosotros las ciencias útiles, la agricultura, las artes, la industria nacional, el comercio... Examinese la estadística de esta vasta y rica nación, y se notará progresivamente su decadencia y despoblación...Degradados los españoles de la altura de su antiguo poder y sabiduría, al mismo tiempo que perdían su energía y libertad, caían en el más espantoso abatimiento, perdían su preponderancia y se entregaban insensiblemente al apocamiento y esclavitud...De una España ilustrada, vino a parar en una agradable superstición y en un orgulloso fanatismo».

${ }^{121}$ Cabe destacar la actitud del Obispo de Orense, Oviedo, del Arzobispo de Santiago Músquiz, así como de los Obispos de Astorga, Oviedo, Lérida, Tortosa, Barcelona, Urgel, Teruel, Pamplona Plasencia y Calahorra; en Waler.M.J. Historia de la Inquisición española. pág. 371. Wdimar Libros. Madrid, 2004.

122 El 27 de junio, la Regencia acordaba la expulsión del Nuncio, dando cuenta de ello a las Cortes, y el 9 de julio se le daban a Gravina 24 horas para abandonar el país.

123 En Waler.M.J. Historia de la Inquisición española; ob, an, cit. pag 371. 
mandaba se procediera a leer en las parroquias el Decreto de abolición de la Inquisición y el manifiesto de las Cortes que exponían los motivos de dicha abolición, ${ }^{124}$ «Las Cortes generales y extraordinarias, queriendo que lleguen á noticia de todos los fundamentos y razones que ban tenido para abolir la Inquisición, substituyendo en su lugar los Tribunales protectores de la Religión, han venido en decretar y decretan: El Manifiesto, que las mismas Cortes han compuesto con el referido objeto, se leerá por tres domingos consecutivos, contados desde el inmediato en que se reciba la orden, en todas las parroquias de todos los pueblos de la Monarquía, antes del Ofertorio de la Misa mayor; y á la lectura de dicho Manifiesto seguirá la del Decreto de establecimiento de los expresados Tribunales».

La labor de las Cortes gaditanas respecto a la abolición del Santo Oficio en España se completaría mediante los decretos CCXXV, por el que se mandaba quitar de los parajes públicos las pinturas e inscripciones de los castigos impuestos por la Inquisición y sobre todo, por el CCXXVI, que nacionalizaba los bienes que fueron de la Inquisición.

\section{A modo de reflexión}

La Constitución de Cádiz, a pesar de su escasa vigencia, o quizás por ello, ha significado históricamente un mito y paradigma para los liberales españoles, lo fue durante su proceso constituyente, con el retorno del absolutismo y siempre que se emprendía una reforma constitucional en nuestro agitado siglo XIX; sin embargo, como indica Alberto de la Hera »la fama de liberal que desde siempre ha acompañado a aquella Asamblea y a su Constitución de primer texto jurídico-político del liberalismo español, no le proviene en absoluto de su regulación del fenómeno religioso, sino de la total repulsa con la que el restaurado Fernando VII se enfrentó con el texto constitucional, sobre la base capital de la atribución de la soberanía al pueblo y las consecuencias politicas derivadas de tal doctrina» ${ }^{125}$.

Con esta afirmación, que compartimos, no queremos indicar que nuestro primer texto constitucional no contenga claros elementos conformadores del primer Estado de Derecho o Estado Liberal, los tiene y pueden percibirse en la diáfana proclamación de la Soberanía Nacional, la división de poderes, la seguridad jurídica, el imperio de la ley etc.; sin embargo, hay dos aspectos en los que a través del texto percibimos ciertas carencias para proclamarlo como un Estado de De-

124 Decreto CCXXIV de 22 de febrero de 1813.

125 Alberto de la Hera (2011); «El artículo 12 de la Constitución de Cádiz y la Religión Católica». En «Cortes y Constitución de Cádiz 200 años» Tomo II, Ed. Espasa, Madrid, pág. 696. 
recho de características similares al norteamericano de 1787 o al francés de 1791; estos aspectos, en la opinión que sostenemos serían:

a) La ausencia de un poder constituyente pleno.

b) La confesionalidad religiosa excluyente e intolerante proclamada en el texto.

En el primer caso, podemos considerar, que la Magna Asamblea gaditana, teóricamente expresión del poder constituyente de la Nación reunido para la conformación de nuestro primer Estado Constitucional, se nos presenta, en la opinión que sostenemos, como un poder constituyente, no plenamente originario, sino derivado de la existencia de otros poderes constituidos previamente, a los que no puede sustituir y con los que su capacidad de reforma no es plena, tales como el Poder Real y la Iglesia, verdaderos conformadores del Estado el primero y de la Nación el segundo. No es la única vez que ello ha ocurrido en nuestra convulsa historia constitucional, pues aún a riego de cometer alguna imprecisión histórica podría sostenerse que las únicas veces que nuestro poder constituyente ha sido pleno sería en el correspondiente al texto de 1869, en la malograda Constitución de 1873 y en el republicano de 1931.

En el segundo aspecto, la confesionalidad excluyente del Estado, no exenta de dogmas de la religión proclamada, se nos presenta no como una manifestación sociológica de la Nación, como ocurre con los primeros textos de Dinamarca o Islandia por ejemplo, sino como una barrera o limitación del desarrollo de los valores y principios del Estado de Derecho; así, derechos como la libertad de imprenta, de expresión, conciencia, etc, e incluso el ejercicio de determinados poderes se nos presentan como vacíos de contenido, o muy disminuidos en su ejercicio.

Ello no obsta, para que podamos afirmar rotundamente, que nuestro primer texto constitucional abre una senda nueva en nuestra historia política, social y económica. Nuestros constituyentes hicieron lo posible por poner fin al Antiguo Régimen y así hubiera sido de no haberlo impedido el Absolutismo español y europeo; en ese aspecto, su actitud fue intransigente, no lo fue en otros aspectos como el religioso, aunque consiguieron notables éxitos como la abolición del Tribunal de la Inquisición, que representa mucho más que la mera supresión de una institución propia del Antiguo Régimen, barrida por el naciente Estado Liberal, en cuyo seno ya no tenía cabida. Su actuación respecto a la religión estuvo supeditada al interés general de proclamar un texto que pusiera fin al Antiguo Régimen, y al reconocimiento de la histórica confesionalidad católica no sólo del Estado, sino de la Nación.

Simplemente se limitaron a abrir un camino que como indicara el propio Argüelles en unas de primeras intervenciones en Cortes, «La Constitución como ley fundamental, debe redactarse de forma abstracta, de tal forma, que sean las Cortes suce- 
sivas las que introduzcan las alteraciones que crean conveniente en la legislacion, sin prescribirles más límites que el que ellas crean oportunos» El mismo político asturiano se referiría años después a este punto explicando la actuación de los liberales al respecto, «para establecer la doctrina contraria bubiera sido necesario luchar frente a frente con toda la violencia y furia teológica del clero, cuyos efectos demasiado experimentados estaban ya, así dentro como fuera de las Cortes. Por eso se creyó prudente dejar al tiempo, al progreso de las luces,...» ${ }^{126}$.

En todo caso, las Cortes de Cádiz y su sector más liberal en concreto inician un camino ajeno a la confrontación con la Iglesia en su ámbito religioso e ideológico, que se desarrollará en el resto del siglo, tendente sólo a desmantelar a la Iglesia Católica en su poder social y económico, sin aventurarse en planteamientos de otra naturaleza.

Title:

\section{TREATMENT RELIGIOUS ESTABLISHMENT OF CADIZ}

\section{Summary:}

1. Introduction. 2. The importance of religion in the drafting of the constitution. 3. Religious treatment in the constitucional text. 4. Legislation passed on inssues regarding the Church.

\section{Resumen:}

El artículo analiza el tratamiento otorgado a la Religión católica en la Constitución de Cádiz. A este respecto, comienza destacando la importancia social de esta religión en la configuración de la nación española, que se refleja en la composición de la Cámara. Los miembros conservadores y clérigos debatieron con los liberales sobre el tratamiento que la Constitución debía dar a la religión católica. Se constata la dificultad de compatibilizar la confesionalidad católica de la Constitución de 1812 con los principios del Estado Liberal. Asimismo, se estudia la legislación en materia religiosa que se aprobó durante este periodo.

\section{Abstract: \\ The article explores the treatment given to the Catholic faith by the fra- mers of the Constitution of Cadiz. At this respect, it starts by the social}

126 Examen histórico de la reforma constitucional que hicieron las cortes generales y extraordinarias...»Vol. I. Londres 1835, pág. 325. 
importance of this faith in the configuration of the Spanish nation, which is reflected in the composition of the chamber. Conservative and clergy members debated with the liberals on the treatment the constitution should give to the Catholic faith. The exclusive Catholic faith of the 1812 constitution and its difficult implementation within the principles of the Liberal State are remarked. It equally studies the legislation passed on religious matters by the ordinary legislature during this period.

\section{Palabras claves:}

Religión, Constitución, Poder Constituyente, Estado Confesional, Iglesia, Regalismo, Libertad religiosa, Estado Laico, Libertad de imprenta, Inquisición.

Key words:

Religion, Constitution, Constituent Power, State Confessional, Church, Gifts, religious Freedom, Secular State, Freedom of speech, Inquisition. 
